\title{
ESTUDO DO PROCESSO DE TRANSFERENNCIA DA IMUNIDADE PASSIVA EM EQUINOS
}

\author{
CARLA MARIA DE MEO-SCOTONI \\ Engenheira Agrônoma
}

Orientador: Prof. Dr. RAUL MACHADO NETO

Dissertação apresentada à Escola Superior de Agricultura "Luiz de Queiroz", da Universidade de São Paulo, para obtenção do título de Mestre em Agronomia - Área de Concentração: Nutrição Animal e Pastagens.

\author{
PIRACICABA \\ Estado de São Paulo - Brasil \\ Janeiro -1988
}


Meo-Scotoni, Carla Maria de

M55le Estudo do processo de transferencia da imunida de passiva em equinos. Piracicaba, 1988.

$72 p$.

Diss.(Mestre) - ESALQ

Bibliografia.

1. Eqüino - Imunidade - Transferência 2. Imuno logia veterinária I. Escola Superior de Agricultu ra Luiz de Queiroz, Piracicaba

CDD 636.10896079 
ESTUDO DO PROCESSO DE TRANSFERENCIA DA IMUNIDADE PASSIVA DE EQUINOS

Carla Maria de Meo-Scotoni

Aprovada em: 05/01/1989

Comissão Julgadora:

Prof. Dr. Raul Machado Neto

ESALQ/USP

Prof. Dr. Celso Boin

ESALQ/USP

Dr. Airton Manzano

EMBRABA/S. Carlos

Prof. Dr. RAUL MACHADO NETO

Orientador 
ii.

$\bar{A}$

minha familia,

pelo apoio e incentivo.

Ao meu marido, Camillo, pelo apoio, incentivo

$e$ desprendimento durante as horas dificeis. 


\section{AGRADEC IMENTOS}

Ao Prof. Dr. Raul Machado Neto, orientador e amigo, pela dedicação e paciência com que me orientou na condução deste trabalho e especialmente pelo enorme conhecimento partilhado;

Ao Prof. Dr. Irineu Umberto Packer pelo valioso apoio e su gestões recebidos;

A Drå Marinêia de Lara Haddad pela colaboração na análise estatística;

Ao Prof. Dr. João Gustavo Brasil Caruso e à Sra. Cleomar M. de C. Miguel, pela anälise das amostras de colostro;

Ao Sr. Josê Francisco de Oliveira, titular do Haras Rancho Nativo, pelas facilidades colocadas à disposição, que permitiram a realização deste trabalho;

Aos funcionários do Haras Rancho Nativo, especialmente ao Sr. Edgar Cunha pela eficiente colaboração prestada;

Aos colegas e funcionârios do Depto. de Zoologia da Escola Superior de Agricultura "Luiz de Queiroz" por toda cola boração e ambiente de trabalho proporcionados;

Ao CNPq pela colaboração no suporte financeiro deste projeto;

E finalmente, a todos aqueles que direta ou indiretamen te deram sua colaboração tornando possível a realização deste estudo. 
INDICE

Pâgina

LISTA DE FIGURAS $\ldots \ldots \ldots \ldots \ldots \ldots \ldots \ldots \ldots \ldots \ldots \ldots \ldots \ldots \ldots \ldots$

LISTA DE TABELAS $\ldots \ldots \ldots \ldots \ldots \ldots \ldots \ldots \ldots \ldots \ldots \ldots \ldots \ldots \ldots \ldots \ldots$

RESUMO $\ldots \ldots \ldots \ldots \ldots \ldots \ldots \ldots \ldots \ldots \ldots \ldots \ldots \ldots \ldots \ldots \ldots \ldots$

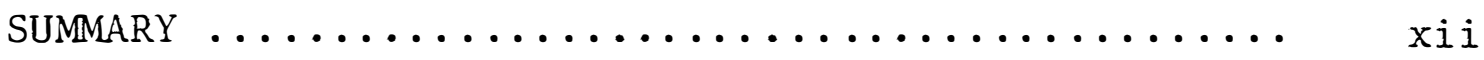

1. INTRODUÇAO $\ldots \ldots \ldots \ldots \ldots \ldots \ldots \ldots \ldots \ldots \ldots \ldots \ldots \ldots \ldots$

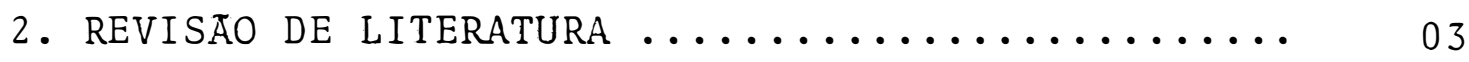



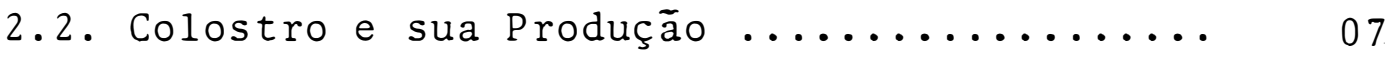

2.3. Imunoglobulinas $\ldots \ldots \ldots \ldots \ldots \ldots \ldots \ldots . \ldots \ldots \ldots$

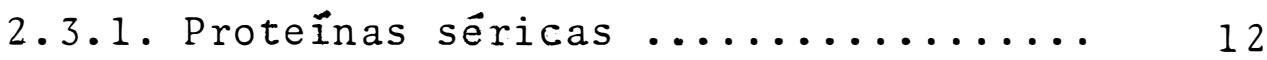

2.3.2. Classes de imunoglobulinas ........ 13

2.4. Mecanismos e Duração da Absorção das Proteí nas do Colostro ................... 17

2.5. Falhas na Transferência de Imunoglobulinas. 23

2.6. Efeitos Deletêrios Associados ao Processo. 29

2.7. Nutrição x Nível Imunológico ........... 32

3. MATERIAL E METOdOS $\ldots \ldots \ldots \ldots \ldots \ldots \ldots \ldots \ldots \ldots \ldots \ldots \ldots \ldots \ldots$

3.1 . Local ....................... 34



3.3. Amostragem de Colostro ............. 35

3.4. Amostragem de Sangue ............... 36

3.5. Análise das Amostras ............... 37

3.6. Delineamento Experimental ........... 40 
4. RESUltados E discussAo .................. 42 4.1. Variação da IgG Sérica em Eguas ......... 42

4.2. Proteina Total do Colostro ............ 46

4.3. Imunoglobulinas Séricas dos Potros ....... 50

5. CONCLUSOES $\ldots \ldots \ldots \ldots \ldots \ldots \ldots \ldots \ldots \ldots \ldots \ldots \ldots \ldots \ldots \ldots \ldots \ldots$

REFERENCIAS BIBLIOGRĀFICAS $\ldots \ldots \ldots \ldots \ldots \ldots \ldots \ldots \ldots \ldots$

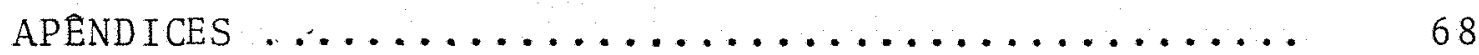




\section{LISTA DE FIGURAS}

FIGURA i ${ }^{\circ}$

Pāgina

01

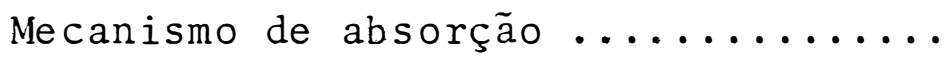

02

Ficha de controle de amostragem .....

03

Variação de IgG sérica (mg/ml) em éguas da raça Mangalarda e PSI ......

04

Variação da Ig sërica (Unidades ZST) em potros das raças Mangalarga e An-



05

Comparação do nível de Ig sérica de potros com o nîvel mẻdio do adulto... 
vii.

\section{LISTA DE TABELAS}

01 Transmissão da imunidade passiva ..... transferência de imunoglobulinas da mãe para o feto via placenta ou colostro..

03 Comparação da composição do colostro com a do leite normal obtido 2 a 3 semanas apōs parição para 3 espécies .........

04 Tempo de absorção em potros .........

05 Concentração de IgG sérica $\ldots \ldots \ldots \ldots$

06 Concentração média de Ig em colostro e soro de potros correlacionada com a gra vidade especifica do colostro........

0.7 Variação de IgG sérica (mg/mI \pm EPM)

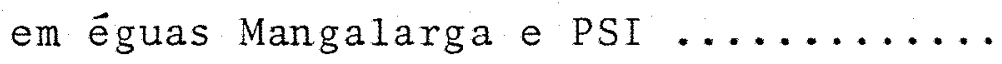

08 Análise da variância para estudo do efei to de raça e de período de amostragem na flutuação de IgG sêrica em éguas .....

09 Anâlise da variância para estudo do efei to de raça na PT do colostro de éguas. 
viii.

TABELA N $N^{\circ}$

Pāgina

10 Niveis de IgG do colostro de éguas PSI e de IgG sérica em potros da raça AngloÁrabe no pico máximo de absorção ......

11. Niveis de IgG do colostro e de IgG sêrica em potros da raça Mangalarga no pico mäximo de absorção $\ldots \ldots \ldots \ldots \ldots \ldots \ldots$

12 Anälise da variância para estudo do efe $\underline{i}$ to de raça na concentração de IgG sérica de potros no ponto de máxima absorção

13 Anālise da variância para estudo do efei to de raça na absorçāo de IgG do colostro pelos potros ................ 50

14 Anâlise da variância para estudo do efe to de raça na concentração de Ig sérica de potros nos diferentes pontos de




ix.

ESTUDO DO PROCESSO DE TRANSFERENCIA DA IMUNIDADE PASSIVA EM EQUINOS

\author{
Autor: CARLA MARIA DE MEO-SCOTONI \\ Orientador: Prof. Dr. RAUL MACHADO NETO
}

\title{
RESUMO
}

Os objetivos deste trabalho foram:

1) determinar a variação de IgG sérica em éguas das raças Mangalarga e PSI* no periodo que antecede ao parto;

2) determinar a concentração de proteina total do colostro das ëguas;

3. estudar o comportamento imunológico dos po tros das raças Mangalarga e Anglo-Arabe.

Foram utilizadas 5 ëguas Mangalarga e 5 éguas PSI para anâlise do colostro; 6 éguas Mangalarga e 7 PSI para anālise de soro; e 6 potros Mangalarga e 7 potros Ang10Arabes para análise de soro. As amostras de colostro foram coletadas imediatamente após o parto, antes da 1 a mamada; as amostras de sangue foram retiradas da veia jugular, aproxima damente $10 \mathrm{ml}$ por animal em cinco datas anteriores ao parto e no momento do parto para éguas; e no momento do nascimen-

* PSI = Puro Sangue Inglês. 
to, às 24 e 48 horas, e aos $5,10,15,20,25,30,40,50,60$ e 70 dias após o nascimento para potros.

As amostras de sangue das ëguas foram analis a das por Imunodifusão Radial, e dos potros pelo método de ZST ("zinc sulfate turbidity"). As amostras de colostro foram analisadas quanto a proteína total (PT) pelo método MicroKjeldahI e considerou-se que $40 \%$ da PT do colostro correspon de a IgG.

A anâlise estatistica dos resultados obtidos com o colostro, mostrou que a PT é maior $(\mathrm{P}<0,01)$ no colos tro de éguas PSI do que no colostro das Mangalargas, o que sugere tambëm maior concentração de imunoglobulinas.

$A$ anâlise de variância dos dados das êguas mos trou que a concentração de IgG $(\mathrm{mg} / \mathrm{ml})$ sérica em éguas PSI é estatisticamente superior $(P<0,05)$, o que indica efeito de raça sobre esta variâvel. A mesma anâlise indicou que a interação raça vs. período não é significativa, não havendo por tanto flutuação de IgG sërica no período prë-parto.

Para a anâlise dos resultados dos potros foram testados modelos matemáticos que estudam o processo biológico de aquisiçāo de imunidade passiva mo período observa do; para a raça Mangalarga:

$$
\begin{aligned}
\mathrm{y} & =23,9274-0,39766 \mathrm{x}+6,4675 \cdot 10^{-3} \mathrm{x}^{2}, \\
\mathrm{r} & =0,91 \\
\mathrm{~F} & =20,3^{* *} ;
\end{aligned}
$$

e para a raça Anglo-Ârabe: 


$$
y=34,161-0,756062 x+0,015604 x^{2}-1,013.10^{4} x^{3}
$$

com

$$
\mathrm{r}=0,96
$$$$
\mathrm{F}=26,5^{* *} \text {. }
$$

Deste trabalho, foi possivel concluir:

1. Apesar de não ter sido detectada queda da IgG sêrica nas êguas antes do parto, a transferência de imunidade passiva ocorreu eficientemente;

2. As concentraçōes de IgG sêrica e de PT do colostro de éguas PSI foram significativamente superiores em comparação com as Mangalarga;

3. Quanto mais amarelado e viscoso era o coIostro, maior sua concentração de PT;

4. A presença de grande quantidade de IgG pas siva no sangue dos potros retardou o estabelecimento de niveis normais de Ig; *

5. Animais que adquiriram menor quantidade de IgG passiva apresentaram resposta mais intensa de produção endógena de Ig;

6. A concentração estimada de IgG no colostro apresentou correlação positiva com a concentração sërica de IgG nos potros no pico de máxima absorção.

\footnotetext{
* Ig $=$ Imunoglobulina $G+M+A+D+E$
} 
Author: CARLA MARIA DE MEO-SCOTONI Adviser: Prof. Dr. RAUL MACHADO NETO

\section{SUMMARY}

The objectives of the present work were:

1) to define the blood IgG flutuaction in Mangalarga and Thoroughbred (TB) mares prior to parturition; 2) to define the colostrum total protein of these mares;

3 ) and to study the immunological behavior of the Mangalarga and Angle-Arabian foals.

Five Mangalarga and five TB mares were used for colostrum analysis; six Mangalarga and seven TB mares for serum analysis and six Mangalarga and seven Angle-Arabian also for serum analysis. The colostrum samples were taken immediately after foaling, before first suckling; the serum samples were collected from the jugular vein about $10 \mathrm{~m} 1$ each animal at intervals of $4,3,2$ and 1 week prior to parturition and at the time of parturition for mares; and at 24 and 48 hours, and at $5,10,15,20,25,30,40,50,60$ and 70 days after birth for foals.

The mares serum samples were analysed by RID 
(single radial immunidifusion), and the foal samples ZST (zinc sulfate turbidity) method. The colostrum samples were analysed for total protein (TP) by Micro-KjeldahI method, and $40 \%$ of the TP of colostrum were considered to be IgG.

The statistical analysis obtained with the colostrum showed that TP is higher in TB compared to Mangalarga $(P<0.01)$, what suggests also higher immunoglobulin concentration.

The analysis of variance of the mares data showed that the IgG $(\mathrm{mg} / \mathrm{ml})$ serum concentration was higher in $\mathrm{TB}$ compared to Mangalarga $(\mathrm{P}<0.05)$, what indicates racial effect for the parameter. The same analysis showed that the relationship between breed and time of sampling is not significative indicating no detectable serum IgG fluctuation prior to parturation.

To analyse the results obtained with foals, mathematical models were tested which studies the biological process of passive immunity transfer in this period of observation, for the Mangalarga;

$$
\begin{aligned}
& y=23.9074-0.39766 x+6.4675 .10^{-3} x^{2} \\
& r=0.91 \\
& F=20.3 *
\end{aligned}
$$

and for the TB:

$$
\begin{aligned}
& y=34.161-0.756062 x+0.015604 x^{2}-1.013 .10^{-3} x^{3} \\
& r=0.96 \\
& F=26.5^{* *} .
\end{aligned}
$$


xiv.

The results of this study permitted the following conclusions:

1. Although decrease in serological IgG levels were not observed, the transference of passive immunity ocur red efficiently;

2. The serum IgG and the colostrum TP of the TB mares were higher compared to the Mangalarga mares;

3. The more yellow the colostrum the higher was its TP concentration;

4. Passive serum IgG in foals in high con centration delayed the stablishment of normal Ig* levels;

5. Foals that adquired low quantities of passive IgG showed more intense response of endogenous Ig production;

6. Colostrum estimated IgG concentration sho wed high correlation with serum IgG concentration of the foals at the point of maximal absorption.

* Ig $=$ Immunoglobulin $\mathrm{G}+\mathrm{M}+\mathrm{A}+\mathrm{D}+\mathrm{E}$ 


\section{INTRODUGÃO}

Embora seja conhecida de longa data a necess $\underline{i}$ dade da ingestão do colostro pelo recém nascido, para seubom desenvolvimento, alguns pontos ainda permanecem obscuros, es pecialmente no caso de equinos nas nossas condiçōes, sobre o que pouco ou quase nada foi feito objetivando um melhor entendimento do processo de aquisição de imunidade passiva por esses animais.

0 tipo de imunidade presente no recém-nascido ê denominado imunidade passiva, visto que deriva de anticorpos maternos, recebidos através de uma determinada via. Esta via de transferência de anticorpos varia com a espécie animal sendo determinada pelo tipo de placenta característico de cada espécie.

Os equinos, ao contrário dos primatas e roedo res, possuem um tipo de placenta que impossibilita a passagem intra-uterina de anticorpos. Daí, o colostro constituír se na única fonte de anticorpos para o recêm-nascido.

Assim, esse trabalho foi proposto com os seguintes objetivos: 
1. determinação da variação da concentração de imunoglobulinas séricas de éguas das raças Mangalarga e Puro Sangue Inglês no período que antecede ao parto;

2. avaliação da PT do colostro de éguas das raças Mangalarga e Puro Sangue Inglês;

3. estudo do comportamento imunológico de potros das raças Mangalarga e Anglo-Arabe.

A determinação dos parâmetros acima descritos visa ao estabelecimento de um manejo mais eficiente do potro recém-nascido. 


\section{REVISÃO DE LITERATURA}

\subsection{Imunidade Passiva}

Um componente importante do mecanismo de defe sa dos mamíferos é sua capacidade de produzir anticorpos em resposta a microrganismos invasores e outras substâncias antigênicas. O ungulado nasce sem anticorpos circulantes e a proteção ê conseguida atravês da transmissāo passiva de imunoglubulinas da mäe para o recém-nascido (EARLE, 1935; BRUNNER et alii, 1948; BRAMBELL, 1958; MORRIS, 1968; ROUSE, 1971; JEFFCOTT, 1972; SIMPSON-MORGAN \& SMEATON, 1972; OLIVEIRA et alii, 1980a).

Inümeros estudos (BOYD, 1972; PLATT, 1973; JEFE COTT, 1275; MCGUIRE et alii, 1975; TOWSEND et alii, 1983; LE BLANC et alii, 1986), sugerem uma estreita relação entre morbide $z$ e mortalidade de potros recem nascidos e a concentração de imunoglobulinas séricas derivadas do colostro.

JEFFCOTT (1972) fez uma revisão clässica bastante completa sobre o assunto: "a imunologia como ciência começou por volta de 1890. com o trabalho pioneiro de Emil von Behring e Paul Erlich. Von Behring e Kitasato (1980) desco- 
briram a antitoxina diftérica e Erlich padronizou-a aumentan do suas potencialidades na profilaxia. Em 1892 Erlich reconheceu diferenças importantes entre imunidade passiva e ativa. Famulener (1912) foi o primeiro a reconhecer a importân cia imunológica do colostro; ele demonstrou a ausência de transmissão de anticorpos via placenta em carneiros e mostrou um râpido aumento do nível de anticorpos apōs ingestão de colostro. Em 1922, Smith \& Little estabeleceram a importância do colostro para a sobrevivência do bezerro recém-nas cido".

Os anticorpos produzidos pela mãe e presentes em sua circulação são transmitidos ao jovem e atingem concen trações semelhantes às do soro dela. Essa transmissão pode ocorrer antes do nascimento, após ou ambos (Tabela 1). A transmissão é totalmente pré-natal em cobaias, coelhos e humanos; parcialmente pré-natal em cães e roedores e exclusiva mente pós-natal em bovinos, caprinos, ovinos, suínos e equinos (BRAMBELL, 1958).

Os recém-nascidos ruminantes, suínos e equinos nascem com apenas traços de gamaglobulina no sangue. As gamaglobulinas concentradas no colostro são absorvidas pela mucosa intestinal do animal jovem após a primeira mamada. Es se processo é tāo rāpido que em algumas horas o soro do animal jovem atinge o nível normal, equivalente ao nível de gamaglobulina do soro materno. Nesses animais a capacidade de absorver os anticorpos pela mucosa intestinal é perdida em 36 h (BRAMBELL, 1958). 
Tabela 1. Transmissāo da imunidade passiva.

\section{Transmissão}

Espécies

\section{Prê-natal Pós-natal}

\begin{tabular}{lcc}
\hline Bovinos, caprinos, ovinos & 0 & $++(36 \mathrm{~h})^{*}$ \\
Suinos & 0 & $+++(36 \mathrm{~h})$ \\
Equinos & 0 & $+++(36 \mathrm{~h})$ \\
Cães & + & $++(10 \mathrm{dias})$ \\
Camundongos & + & $++(16 \mathrm{dias})$ \\
Cobaias & +++ & 0 \\
Coelhos & +++ & 0 \\
Humanos & +++ & 0 \\
\hline
\end{tabular}

Fonte: BRAMBELL (1958)

* Tempo de absorção

Mais especificamente sobre cavalos, TIZARD (1985) relata que o período de gestação da égua é de cerca de 340 dias; cêlulas linfóides são primeiramente observadas no timo fetal em torno de 60 a 80 dias após a concepção. Elas sāo encontradas no gânglio linfático mesentérico e na lâmina pröpria intestinal aos 90 dias e no baço aos 175 dias. Os Iinfócitos de sangue periférico aparecem em torno de 80 dias. 0 feto do cavalo pode responder ao colifago $\mathrm{T}_{2}$ aos 200 dias após a concepçāo e à encefalite equina venezuelana aos 230 dias. Nos potros recém-nascidos normais observa-se uma pequena quantidade de IgM sérica antes da amamentaçāo. Apesar disso, afirma-se que os plasmöcitos näo são normalmente ob- 
servados até cerca de 240 dias de gestação. Ainda segundo es te autor a via pela qual os anticorpos maternos alcançam o feto é determinada pela natureza da barreira placentäria (Ta bela 2).

Tabela 2. Relaçāo entre os tipos de placenta e transferência de imunoglobulinas da mãe para o feto via placenta ou colostro.

\begin{tabular}{|c|c|c|c|c|}
\hline \multirow{2}{*}{ Espécies } & \multirow{2}{*}{$\begin{array}{l}\text { Tipo de } \\
\text { placentaçāo }\end{array}$} & \multirow{2}{*}{$\begin{array}{l}\text { Camadas de } \\
\text { tecidos que } \\
\text { se interpöm } \\
\text { entre as cir } \\
\text { culaçoes mater } \\
\text { na e fetal }\end{array}$} & \multicolumn{2}{|c|}{$\begin{array}{l}\text { Transferência } \\
\text { de imunoglobulinas }\end{array}$} \\
\hline & & & Placenta & Colostro \\
\hline $\begin{array}{l}\text { Porco, Cavalo, } \\
\text { jumento }\end{array}$ & Epiteliocorial & $6 *$ & 0 & +++ \\
\hline Ruminantes & Sindesmocorial & 5 & 0 & +++ \\
\hline Cáo e gato & Endoteliocorial & 4 & + & ++ \\
\hline Primatas & Hemocorial & 3 & ++ & + \\
\hline Roedores & Hemendotelial & 1 & +++ & + \\
\hline
\end{tabular}

* Endotélio capilar materno, tecido uterino, epitélio uterino, epitélio cariônico, tecido conectivo fetal e endotélio capilar fetal. Fonte: TIZARD (1985).

Em humanos e outros primatas a placenta e hemocorial, isto é, o sangue materno estä em contato direto com - trofoblasto. Este tipo de placenta permite a transferência de ao feto, mas não 
de IgG, IgA ou IgE. Deste modo, a IgG materna pode entrar na circulação sanguinea fetal e a criança pode ter niveis de IgG circulante comparâveis aos de sua mãe. Como resultado dessa transferência de IgG a criança fica protegida contra in fecção septicêmica. Cães e gatos possuem placenta endètelio corial, onde o epitêlio coriônico está em contato com o endo tẻlio dos capilares maternos. Nestas espécies, uma pequena quantidade de IgG (5 a $10 \%)$ pode transferir-se da mãe para a cria, mas a maior parte é obtida por meio do colostro. A placenta dos ruminantes é sindesmocorial, isto ê o epitélio coriônico está em contato direto com os tecidos uterinos enquanto que a placenta de cavalos e porcos é epiteliocorial e o epitêlio coriónico fetal estâ em contato como epitélio ute rino intacto. Em animais com os tipos de placenta citados acima, a passagem placentâria de molêculas de imunoglobulinas $\hat{e}$ totalmente impedida, e os recêm-nascidos dessas espécies säo inteiramente dependentes dos anticorpos obtidos do colos tro.

\subsection{Colostro e sua Produgão}

Colostro, primeira secreção läctea produzida após a parição tem importante função imunológica para o recëm-nascido. Contém alta concentração de imunoglobulinas e certas vitaminas, mas é relativamente pobre em lactose, gordura e cálcio no caso de éguas (JEFFCOTT, 1972).

Segundo 
JEFFCOTT (1975) em mëdia a secreção de colostro em éguas é de $160 \mathrm{ml} /$ hora durante as primeiras 24 horas após o parto. $\mathrm{Na}$ Tabela 3 podemos verificar a composiçāo do colostro compa rado com leite obtido na $3 a ̈$ semana pós-parto em três espécies diferentes.

Tabela 3. Comparação da composição do colostro com a do 1eite normal obtido $2-3$ semanas apôs pariçāo para 3 espëcies.

\begin{tabular}{|c|c|c|c|c|c|c|}
\hline & \multicolumn{2}{|c|}{ Vaca Holandesa } & \multicolumn{2}{|c|}{ Porca } & \multicolumn{2}{|c|}{ Agua $a$} \\
\hline & Colostro & Leite ${ }^{b}$ & Colostro & Leiteb & Colostro & Leitec \\
\hline Sólidos totais $\left(\frac{\bullet}{0}\right)$ & 23,9 & 12,9 & 20,5 & 16,9 & 25,2 & 11,3 \\
\hline Gordura $(\because)$ & 6,7 & 4,0 & 5,8 & 5,4 & 0,7 & 2,0 \\
\hline Proteína $(\%)$ & 14,0 & 3,1 & 10,6 & 5,1 & 19,1 & 2,7 \\
\hline Lactose $(:)$ & 2,7 & 5,0 & 3,4 & 5,7 & 4,6 & 6,1 \\
\hline Cinza (\%) & 1,11 & 0,74 & 0,73 & 0,71 & 7,72 & 0,50 \\
\hline Grav. Específica & 1,056 & 1,032 & - & - & 1,076 & 1,035 \\
\hline
\end{tabular}

a - ULLREY et alii, 1966

b - 2 semanas aposs parto

c - 3 semanas apôs parto

Fonte: SCHIMIDT (1971)

Leite e colostro contêm essencialmente 2 grupos de proteínas (Schultze \& Heremans, 1966, citados por JEFFCOTT, 1972): 
a) Proteinas especificas do leite:

- Caseína

- B-lactoglobulina

- $\alpha$-1actoalbumina

- lactofenina

- proteínas especificas menores

- enzimas e constituintes nāo identificados

b) Proteinas derivadas do plasma:

- albumina sërica

- imonoglubilinas - IgA, IgM, IgG

- $\alpha_{1}$ - antitripsina

- ácido $\alpha_{1}$ glicoproteina

- $B_{1} A C$ - globulina

A proteína do colostro dos equinos só foi estudada com respeito aos componentes imunológicos (JEFFCOTT, 1972). A imunoglobulina predominante no colostro humano é IgA do tipo secretor; IgM e IgG ocorrem em menor quantidade (ROUSE \& INGRAM, 1970; PORTER, 1979). No cavalo, como nos outros ungulados IgG ê a principal imunoglobulina do colostro. Aparentemente as Ig do colostro são transportadas sele tivamente do sangue e não sintetizadas na glândula mamária, como em humanos. Segundo PORTER (1979), IgA não é predominante no colostro de espécies econômicas. Suinos e bovinos apresentam rápido declínio de IgG o que pode ser entendido co mo uma maneira de econominar IgG materno uma vez que esta 
classe é transferida quase exclusivamente por um processo transudativo no epitélio da glândula mamâria. Em suínos IgA pre domina no leite (síntese 1ocal) e nos bovinos a glândula mamäria apresenta-se deficiente em sintese de Ig. IgA é mais efetiva para imunização local contra $E$. coli. 0 mesmo autor ainda relata que a imunização materna ( $\mathrm{gGG}$ ) influencia o "sta tus" imunologico do neo-nato interferindo no processo de desenvolvimento de imunidade ativa. Os anticorpos adquiridos via colostro regulam a resposta imune, inibindo desenvolvimen to de células produtoras de anticorpos, o que concorda com o trabalho de MACHADO NETO \& PACKER (1986), aparentemente por mecanismo que envolve eliminação de antígenos; e tambêm atua por um mecanismo que envolve anticorpos citofílicos. Ao contrário do IgG, o IgM estimula o desenvolvimento dessas células.

Em amostras de colostro de pôneis obtidas antes da 1 a mamada a proteína total era 2 vezes a proteína total do soro (ROUSE \& INGRAM, 1970). No mesmo estudo, esses autores verificaram que IgG variou de $31 \mathrm{mg} / \mathrm{ml}$ a $60 \mathrm{mg} / \mathrm{ml}$, o que corresponde de 21,8 a $43,5 \%$ da proteína total do colostro. Ainda demonstraram que ocorre grande diminuição de PT e Ig no colostro com o passar do tempo após o parto:

$$
\begin{aligned}
& 0-3 \text { horas após parto }-40 \% \mathrm{PT}=\mathrm{IgG} \\
& 9-24 \text { horas após parto }-8,8 \% \mathrm{PT}=\mathrm{IgG} \\
& 1-5 \text { dias após parto }-2,13 \% \mathrm{PT}=\mathrm{Ig} G
\end{aligned}
$$


Dessa forma, um potro ativo muda a secreçāo de colostro para leite em cerca de 12 horas.

Num estudo mais recente, PEARSON et alii (1984) determinaram a concentração de IgG do colostro em éguas das raças Árabe e PSI e verificaram:

$$
\text { To(parto) } \begin{aligned}
\operatorname{IgG} & =96,81 \mathrm{mg} / \mathrm{ml} \text { (Arabe) } \\
\operatorname{IgG} & =46,08 \mathrm{mg} / \mathrm{ml} \text { (PSI) }
\end{aligned}
$$

Além disso determinaram o tempo necessário para que o colostro reduzisse sua concentração de IgG para $10 \mathrm{mg} / \mathrm{ml}$ :

$\mathrm{T}_{10}=19,1$ horas (Arabe)
$\mathrm{T}_{10}=8,9$ horas (PSI)

Esses achados apontaram diferenças relevantes entre raças, porém os autores consideram que há grande varia ção entre individuos. A concentraçāo de Ig no colostro sofre influências de:

- idade da māe

- n? de lactaçōes

- produção de colostro

- manejo

Os dados do referido trabalho sāo ainda importantes porque sugerem, com base no $\mathrm{T}_{10}$ que o colostro deve ser coletado nas primeiras 8 horas após o parto para se destinar ao "banco de colostro", assunto que será tratado mais adiante.

Em função da importância que esse assunto tem tido, LE BLANC et alii (1986) desenvolveram um estudo rela- 
cionando concentração de Ig sérica em potros, concentração de Ig no colostro, esta última, medida em colostrômero especialmente desenvolvido para esse proposito, o que permitiu um grande avanço no manejo prätico da transmissão da imunida de passiva.

\subsection{IMUNOGLOBULINAS}

As imunoglobulinas são proteînas globulares cujas cadeias polipeptidicas se dobram firmemente adquirindo estrutura esfêrica ou globular compacta caracterizando sua estrutura terciāria.

\subsubsection{Proteinas sëricas}

Os três grupos principais são:

a) fibrinogênio, que ê produzido no fïgado e que, portanto, ê reduzido em funçāo de lesões hepáticas. No processo de coagulação a maior parte do fibrinogênio ê removido; portanto, o soro contêm pouco ou nenhum fibrinogê nio.

b) albumina - a fraçāo albumina nāo e um grupo homogênio; $2 / 3$ equivalem a mercaptalbulima (que contém 1 
grupo SH livre por mol), hä uma fraçāo não mercaptalbumina e tambëm glicoproteínas.

c) globulinas, que são um grupo muito complexo que inclui:

- mucoproteínas e glicoproteínas

- lipoproteínas

- proteinas fixadoras de metais ( $\mathrm{Fe}$ e $\mathrm{Cu}$ )

- imunoglobulinas - fração das proteínas séricas que è a sede principal dos anticorpos circulantes, as imunoglobuli nas, proteinas intimamente relacionadas que encerram toda a atividade conhecida dos anticorpos do soro. Segundo estudos eletroforêticos, imunológicos e de ultracentrifugação, foram divididos em três principais grupos, na ordem crescente de mobilidade eletroforética:

(1) $r_{2}$ - principal fraçāo encerrando os anticorpos, também designada IgG.

(2) ${ }_{2} A$ ou IgA, que se diferencia da anterior por conter mais carboidrato.

(3) $\beta_{2} M$ ou IgM, fraçāo de maior peso molecular encerrando an ticorpos (HARPER, 19681 .

2.3.2. Classes de imunoglobulinas

IgG - E a principal Ig sintetizada na respos- 
ta secundária; tem habilidade de atravessar a placenta (em humanos) e portanto é a principal linha de defesa contra infecções nas primeiras semanas.

Difunde-se mais prontamente do que as outras Ig para os espaços extracelulares, onde como espécie predominante tem a funçāo principal de neutralizar toxinas bacterianas e complexar microrgnaismos para facilitar a fagocitose: o complexo bactéria/IgG atrai células polimorfonucledas fa gocitóticas que aderem à bactêria através de receptores de superfície.

A taxa de catabolismo de IgG depende diretamen te de sua concentração total.

A sintese é inteiramente governada por estimu lação antigênica, de maneira que em animais "germ free", p.ex,, o nível de IgG é bastante baixo.

- coeficiente de sedimentação: 7S

$-\mathrm{PM}=150.000$

- $\mathrm{n}$ : de unidades bāsicas de 4 peptídeos: 1

- [ ] no soro normal: $8-16 \mathrm{mg} / \mathrm{ml}$

- $\frac{\circ}{\circ}$ Ig total: $80 \%$

- conteũdo de CHO: $3 \%$

E a Ig mais abundante nos fluídos internos, particularmente nos extravasculares, onde combate microrganismos e suas tox $\underline{i}$ nas (ROITT, 1977). 
IgA - Forma polímeros espontaneamente. Aparece seletivamente nas secreçōes sero-mucosas como saliva, lägrima, fluídos nasais, suor, colostro e secreçōes do pulmão e trato gastrointestinal, onde sua função é clara: defender as superficies externas expostas do corpo contra ataque de microrganismos. Aparece nesses fluídos como um dímero estabilizado contra proteólise pela combinação com uma outra proteína.

E sintetizada por células plasmâticas e pode funcionar impedindo a aderência de microrganismos à superfí cie Ias mucosas, evitando assim sua entrada nos tecidos.

- coeficiente de sedimentação: 7S, 9S, IIS

- PM-160.000 e polímeros

- $\mathrm{n}$ : de unidades básicas de 4 peptídeos: $1 ; 2$

- [ ] no soro normal: $1,4-4 \mathrm{mg} / \mathrm{m}$ ]

- : Ig tota1: 13\%

- conteûdo de $\mathrm{CHO}: 8 \%$

IgM - São agentes aglutinantes e citolíticos bastante eficientes. Aparecem prontamente nos casos de infecção e por estarem confinadas aos vasos sanguíneos parecem ser de particular importância nos casos de bacteremia.

As isohemaglutininas (anti-A, anti-B) e vārios anticorpos "naturais" aos microrganismos são IgM.

Os anticorpos para o antígeno tifóide "O" (en dotoxinal e os anticorpos "WR" em sífilis também tendem a ser encontrados nessa classe. 
Parece que IgM precede IgG na fillogenia da res posta imune nos vertebrados.

- coeficiente de sedimentação: 19S

- $\mathrm{PM}=900.000$

- ne de unidades bâsicas de 4 petptídeos: 5

- [ ] normal no soro: $0,5-2 \mathrm{mg} / \mathrm{m} 1$

- : Ig total: $6 \%$

- conteúdo de $\mathrm{CHO}: 12 \%$

IgD - Foi reconhecida através da descoberta da proteina de mieloma que nāo tem a especificidade antigênica da IgG, IgA ou IgM, embora reaja com anticorpos a cadeias leves de Ig e tenha a estrutura básica de 4 peptídeos. E a ûnica classe de Ig suceptível a degradação proteolítica, o que contribui para sua meia vida curta no plasma $(2,8$ dias $)$.

Ocorre na superfície de uma parte dos linfócitos sanguíneos, frequentemente junto com IgM e parece que podem funcionar como receptores antigênicos que interagem mutuamente para o controle de ativaçāo e supressão do linfócito.

- coeficiente de sedimentação: 7S

$-\mathrm{PM}=185.000$

- no de unidades básicas de 4 peptídeos: 1

- [ ] no soro normal: $0-0,4 \mathrm{mg} / \mathrm{ml}$

- $\frac{\circ}{\circ}$ Ig tota1: $1 \%$

- conteủdo de CHO: $13 \%$ 
IgE - Presente em quantidade muito pequena no soro.

Os níveis séricos aumentam conside ravelmente nas infecções por certos parasitas, particularmente helmintos.

- coeficiente de sedimentação: 8S

$-\mathrm{PM}=200.000$

- $\mathrm{n}$ \% de unidades básicas de 4 peptídeos: 1

- [ ] no soro normal: 17-450 $\mathrm{mg} / \mathrm{m} 1$

- $\%$ Ig total: $0,002 \%$

- conteúdo de CHO: $12 \%$

E responsâvel pelos sintomas de alergia atőpi ca (ROITT, 1977).

\subsection{Mecanismo e duragāo da Absorgāo das Proteínas do Colostro}

A placenta da égua é do tipo epiteliocorial difusa, e não permite a passagem de moléculas grandes (JEFFCOTT, 1971, 1974a; TIZARD, 1985); portanto, não hä transmissão de imunoproteínas durante a gestação. Assim, através do colostro, a mãe estâ apta a transmitir ao potro alguma imunidade passiva temporäria, contra uma gama de microrganismos comuns aos quais ela foi previamente exposta (Fig. 1) (em função de sua 
Concentraçāo seletiva

EGUA $\longrightarrow$ de Ig pela glângula mamäria antes do parto para formar

POTRO

Ig passivas retidas no soro gradualmente atê total desapa recimento por volta dos 5 meses

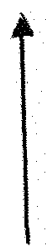

Ig passam para o duto toráxico via 1 infáticos locais a atin gem a circulaçāo sis têmica do potro colostro



Recém-nascido ingeAbsorção é auxiliada por fatores de baixo PM do co- $-\rightarrow \rightarrow$ re Ig através do co lostro lostro logo após $\overline{0}$ nascimento

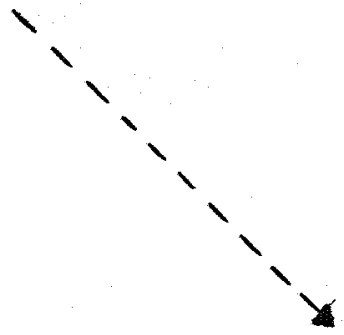

Ig e outras proteinas do leite são absorvidas intactas por células especializadas do intestino delgado.

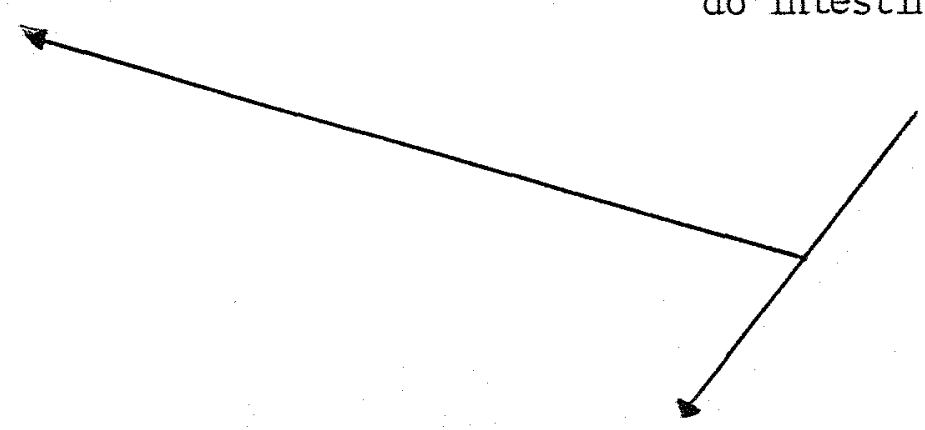

Proteinas do leite de baixo PM sāo excretadas pelos rins produzinco proteinuria tran sitória

Figura 1. Mecanismo de absorçäo Fonte: JEFFCOTT (1974a). 
experiência imunológica). A secreção de colostro ê de curta duração - cai a nível insignificante em 24 horas após o parto (JEFFCOTT, 1974b). O potro recém-nascido geralmente mama colostro durante as 2 ou 3 primeiras horas de vida, e em 6 horas pode-se encontrar alguma gamaglobulina no soro. 0 pico de Ig é atingido em 18 horas de vida e a concentração sérica é semelhante à concentração do soro da māe. Os anticorpos pas sivos declinam gradualmente até estarem completamente ausentes aos 5 meses de idade. Bem antes disso o potro jä mostra sinais de estar apto a se proteger: gamaglobulina endógena é encontrada pela primeira vez após 2 semanas de idade, embora - nível dos adultos não seja alcançado atê os 5 meses de ida de (JEFFCOTT, 1974a).

Transferência de imunidade passiva implica na absorçāo da proteína intacta. Só o intestino delgado do recēm-nascido tem essa capacidade, a nāo ser em certos casos patológicos em adultos. A absorção no recém-nascido é um processo endocitótico, que de acordo com ARGEnzIO è o que se segue:

(1) adsorção da macromolécula na microvilosidade da cêlula adsortiva;

(2) a adsorçāo prossegue até atingir certa con centraçāo nas microvilosidades quando ocor re invaginaçāo com formaçāo de vesículas. Esse processo é dependente de energia para reposição da membrana celular. 
(3) migração do fagossoma para a região supra nuclear onde ocorre coalescência do fagos soma com o lisossoma originando o fagolisossoma, nessas vesículas ocorre digestão intracelular, mas algumas moléculas maiores escapam, migram para a região basolateral, onde são excretadas por um processo inverso da endocitose (exocitose).

(4) passam para o espaço intercelular.

(5) atingem o sistema linfático e finalmente a circulação sistêmica.

A atividade proteolítica da mucosa intestinal é baixa ao nascimento, o que evita a digestāo de macromolécu las de Ig antes de serem transferidas para a circulação do neonato. o colostro tem um fator inibidor da tripsina, que preserva os anticorpos da hidrólise por enzimas pancreáticas. A atividade da pepsina no estômago $\vec{e}$ bastante baixa ao nasci mento e aumenta rapidamente após duas semanas de idade ao mesmo tempo que ocorre um aumento da produçāo de $\mathrm{HCl}$ pelas cêlulas parietais.

JEFFCOTT (1971) determinou que a permeabilida de intestinal a macromoléculas em potros começa a diminuir logo após o nascimento e é um processo gradual que terminaem torno de 24 horas (Tabela 4 ). Esse período coincide com a cessação da proteinúria transitôria. 
Tabela 4. Tempo de absorção em potros.

\begin{tabular}{lcccccc}
\hline & \multicolumn{6}{c}{ Horas após nascimento } \\
\cline { 2 - 6 } & $0-15$ & $16-19$ & $20-22$ & $23-24$ & $26-36$ & 48 \\
\hline No de potros & 12 & 8 & 11 & 8 & 3 & 1 \\
$\begin{array}{l}\text { Absorção dos } \\
\text { marcadores }\end{array}$ & ++ & + & \pm & - & - & - \\
\hline+ absorção & & & & & & \\
- não absorção & & & & & \\
Fonte: JEFFCOTT (1971).
\end{tabular}

JEFFCOTT (1974b) verificou que hâ pouca diferença no tempo para iniciar a produção de imunoglobulina endógena entre potros que não receberam colostro e aqueles que receberam uma quantidade extra de imunoglobulina passiva após - nascimento. O pico de gamaglobulina endógena foi atingido mais cedo em potros que não receberam colostro embora em 3 ou 4 meses o nível tenha sido o mesmo para os dois, resultados que tambēm são sugeridos por MACHADO NETO \& PACKER (1986) tra b.alhando com bezerros. Miller ${ }^{1}$ (1966), citado em JEFFCOTT (1974b) considera que a maturidade imunológica não está vinculada ao processo do nascimento e que fatores ambientais, pre

1 MILLER, J.F.A.O. Immunity in the foetus and the new bom. Brittish Medical Bulletin, 22: 21-26, 1966. 
sumivelmente estimulaçāo antigênica, sejam responsāveis pela expressão da capacidade imunológica. E este parece ser o caso, pelo menos em potros que receberam colostro, nos quais a gamaglobulina passiva mascarou ou retardou a produção de gamaglobulina endógena. A habilidade de sintetizar gamaglobulina $\vec{e}$ detectada após 2 semanas de vida, o que, assumindo-se um período de adaptação de 7 dias para produção, in dica que a competência imunológica se faz presente logo após o nascimento.

McGUIRE et alii (1977) tambëm comentam que "potros nascem com um sistema linfóide razoavelmente imuno competente".

A absorção de anticorpos do colostro é semeThante em potros e bezerros (JEFFCOTT, 1972). Num estudo de absorção, MACDOUGALL (1975) relata que encontrou uma eficiência de absorção de macromolêculas de $50 \pm 16,5 \%$ em bezerras, com eficiência individual variando entre 25 a $75 \%$, e que hā alta correlaçāo entre a quantidade de colostro fornecida e a quantidade de IgG absorvida até $250 \mathrm{~g}$ de IgG em 4 litros de colostro. Outro trabalho de JEFFCOTT (1975) nes se mesmo sentido, obteve $22 \%$ de eficiência de absorçāo; o au tor considera que essa eficiência é obtida se for considera do o "pool" intracelular de IgG (MACDOUGALL, 1975).

De acordo com JEFFCOTT (1975) o colostro contêm substâncias capazes de auxiliar a absorçāo de macromoléculas; em bovinos parecem estar envolvidos dois grupos de 
substâncias: uma fração proteica de baixo peso molecular e fosfato inorgânico e glicose-6-fosfato. A absorção se reduz em $10 \%$ quando o potro não recebe colostro embora o tempo de "fechamento" da mucosa intestinal não se altere; isso pro vavelmente está associado à ausência dos fatores do colostro que melhoram a absorção.

\subsection{Falhas na Transfêrencia de imunoglobulinas}

As falhas no mecanismo de transferência de Ig da māe para o potro têm inümeras causas: a mãe produz colostro com baixa concentração de Ig, que ocorre em éguas de 1 ạ cria, por falha no mecanismo seletivo de Ig do sangue para a glândula mamāria; lactaçāo prematura, fato relativamente comum, é considerada a causa mais importante do baixo nível de imunidade do potro, e pode ser devida a placentitis, gêmeos, separaçāo da placenta ou vazamento; acesso retardado ao coIostro devido a rejeição pela māe, fraqueza ou defeito do po tro; mâ absorçāo intestinal que pode ocorrer em função de "stress" no parto com consequente produção exagerada de adre nocortidóides, hormônios que influenciam a permeabilidade do intestino delgado e podem reduzir ou eliminar a absorção das macromoléculas; e partos prematuros que têm influência sobre produçāo do colostro - éguas paridas antes de 320 dias de ges tação não tiveram tempo ou estímulo hormonal para produção 
de colostro, ou seja, estão fora de sincronia fisiolpogica (JEFFCOT, 1974; MCGUIRE et alii, 1977; RUMBAUGH et alii, 1979).

O trabalho de TOWSEND et alii (1983) mostram que a indução de parto em águas afeta a transferência de imu nidade passiva: indução de parto em 1.1 ëguas resultou em 4 mortes e concentração média de IgG nos potros "induzidos" me nor que nos "controle". As explicações para esses resultados são: volume inadequado de colostro produzido; absorção inadequada pelo potro devido a seu baixo vigor em conjunto com outros fatores que tambêm podem atuar uma vez qye o autor ressalta que hâa grande variação entre indivíduos.

Para detectar falhas na transferência ou baixo nível imune é necessário saber quais valores podem ser atingidos e considerados normais (Tabela 5).

Tabela 5. Concentração de IgG sêrica (mg/ml), dados de vārios autores.

Raça Adulto Potro Autor

Raças pesadas de trabalho

Ponei e PSI

PSI

PSI

Quarto de Milha

Arabe

Bezerros
$8,5-30,0$ $10,5-31,5$

12,25

$-$

$-$

15,0

$-$
$25,0-33,75$ $2,0-33,5$

TOWSEND et alii, 1983 (controle) TOWSEND et alii,1983 (induzido) 15,85 ROUSE, 1971

13,35 McGUIRE et alii, 1977

13,5

19,2

19,8

PEMBERTON et alii, 1980

MCGUIRE \& CRAWFORD, 1973

POPIE \& MCGUIRE, 1976

23,46

MACHADO NETO \& PACKER, 1986 
Hâ forte evidência de alta correlação entre infecções neonatais e imunidade passiva em potros, bezerros e carneiros (JEFFCOTT, 1972). Rossdale ${ }^{1}$, citado em JEFFCOTT (1972), notou que 4 potros doentes apresentaram níveis de proteína total e $\gamma$-globulina abaixo do normal. BOYD (1972), trabalhando com bezerros, chegou às mesmas conclusões. Nesse contexto PFFEIFER \& MCGUIRE (1977) estabeleceu que bezerros com menos de $15,0-20,0 \mathrm{mg} \mathrm{IgG} / \mathrm{ml}$ de soro são mais susceptíveis a infecções e que o nível mínimo para sobrevivência é de $7,5 \mathrm{mg} /$ $\mathrm{m} 1$.

MCGUIRE et alii (1977) verificou falhas na transferência em $24 \%$ dos 87 potros PSI examinados por ele; a alta ocor rência de infecções em animais com deficiência de IgG acentuou ainda mais a importância da transferência de anticorpos do colostro para o recém-nascido. Esse autor examinou tamb.ém um grupo de 11 potros que morreram e verificou que em 10 desses animais o conteủdo de IgG no soro era menor que $4,0 \mathrm{mg} / \mathrm{ml}$ enquanto que a mëdia para potros normais era de $13,35 \mathrm{mg} / \mathrm{m} 1$.

o efeito protetor dos anticorpos maternos é melhor ilustrado em potros com imunodeficiência combinada (CID): mesmo sem um sistema linfóide funcional, a maioria desses animais parece clinicamente normal durante o primeiro

1 ROSSDALE, P.D. A clinical and laboratory assessment of the health status of the new born TB foal Fellowship Thesis, Royal College of Veterinary Surgeans, Londres, 1966. 
mês de vida, enquanto grande quantidade de anticorpos maternos $\vec{e}$ recebida. Em seguida eles se tornam suceptíveis a in fecçōes fatais. Os que apresentam, alëm disso, falha na trans ferência de anticorpos por qualquer outro motivo, sucumbem muito antes do que os que contam com transferência normal (MCGUIRE et alii, 1977).

A CID (combined immunodeficiency) vem a ser um defeito genético na produção de linfócitos $B$ e $T$, de maneira que potros que nascem agamaglobulinêmicos, como jā res saltado anteriormente, são incapazes de sintetizar as imunoproteínas necessārias à sua sobrevivência. Essa doença só foi encontrada em cavalos da raça Arabe e em humanos. A suceptibilidade do indivíduo a doenças infecciosas é pouco conhecida em cavalos; em seres humanos é devida a defeitos genéticos e adquiridos incluindo fatores como: agamaglobulinemia ou hipogamaglobulinemia, ausência de resposta imune das cêlulas, função de macrofagia defeituosa, função de neutrófi los defeituosa e anormalidades complementares (McGUIRE et alii, 1975; POPPIE \& MCGUIRE, 1976).

Embora a importância do colostro para o recêm-nascido esteja bastante bem estabelecida, o fato de que grande parte das infecçōes e mortes é devida a falhas na trans ferência de Ig ainda não é devidamente considerado. Nestes termos, observa-se que a identificação e o tratamento de po tros imuno-deficientes é de elevada importância, especialmen te no caso de equinos onde o valor econômico individual $\vec{e}$ 
elevado. Sob esse aspecto vārios esforços têm-se registrado no sentido de identificar e tratar esse problema a nível de campo (BOYD, 1972; BUENING et alii, 1977; PFEIFFER et alii, 1977; PEMBERTON et alii, 1980; WATSON et a1ii, 1980; KENT \& BLACKMORE, 1985; LE BLANC et alii, 1986).

MCGUIRE et alii (1977) correlacionando e considerando as possiveis causas de falha e a incidência de infecções e morte estabeleceu que potros com menos de 2,0 mg $\mathrm{Ig} / \mathrm{ml}$ de soro apresentam falha na transferência e potros com 2,0-4,0 mg/m1 apresentam falha parcial.

Alguns procedimentos de laboratório são sugeridos para verificar a transferência de Ig materna para o neonato:

- Imunodifusāo radial - antisoro específico con tra o soro do individuo; o tamanho do anel de precipitação com parado com padrōes conhecidos dâ a informação sobre a classe de Ig procurada.

- ZST (Zinc Sulphate Turbidity) - precipita ção química das globulinas com íons metâlicos, leitura em espectrofotômetro.

- Eletroforese do soro - assume-se que as Ig migram com a fração $\gamma$, mas deve-se ressaltar que as Ig não estão totalmente confinadas a essa fração - encontram-se tam bêm na fração $\beta_{1}$.

- Refractometria da proteina total do soro assume-se que as variaçōes de PT refletem a transferência de Ig do colostro porque Ig ê a unica classe de proteina que au menta após a ingestão do colostro. 
- Precipitação com sulfito de södio - baseiase na precipitação das globulinas (RUMBAUGH, 1978; BIERER, 1969).

Uma vez conhecido o nível imunológico do animal, cumpre tratar os que apresentarem falha na transferência. Há duas maneiras de tratar uma falha na transferência: a primeira é fornecer colostro por via oral em mamadeira ou via intubação nasogástrica para potros com menos de 18 até 24 horas de vida. Fornecer 200 a $250 \mathrm{ml}$ de colostro de boa qua lidade (alta concentraçāo de Ig) supre quantidade satisfató ria de IgG sérica (JEFFCOTT, $1974 \mathrm{a}$; RUMBAUGH et alii, 1979; LE BLANC et alii, 1986). A suplementação com colostro supõe a manutenção de um "banco de colostro" e o trabalho de LE BLANC (1986) forne ce dados importantes para esta prätica: "colostro coletado para banco deve ter alta concentração de $\operatorname{IgG}(>70 \mathrm{mg} / \mathrm{m} 1)$. Pa ra isso o colostro pode ser coletado de éguas cujos potros morreram. Uma alternativa é selecionar éguas com alta concentração de IgG". Nesse estudo, ëguas com gravidade especí fica de colostro $\geq 1.090$ têm concentraçāo de IgG $>70,0 \mathrm{mg} /$ ml e seus potros apresentam concentração sérica média de $15,0.4 \mathrm{mg} \mathrm{Ig} / \mathrm{ml}$ de soro às 24 horas.

Nesse sentido a Tabela 6 ilustra a correlação que existe entre concentração de IgG do colostro e concentra çāo sërica dos respectivos potros. 
Tabela 6. Concentração média de Ig em colostro e soro de potros correlacionada com a gravidade específica do colostro.

\begin{tabular}{|c|c|c|}
\hline $\begin{array}{l}\text { Gravidade } \\
\text { específica } \\
\text { colostro }\end{array}$ & $\begin{array}{c}\text { Concentração de } \mathrm{Og} \\
\text { colostro } \\
\text { (mg/ml) }\end{array}$ & $\begin{array}{l}\text { Concentração de Ig } \\
\text { soro de potro } \\
(\mathrm{mg} / \mathrm{ml})\end{array}$ \\
\hline $1,060-1,065$ & $\begin{array}{c}42,28 \\
(30,4-56,8)\end{array}$ & $\begin{array}{c}8,79 \\
\left(5,21^{-13,3)}\right.\end{array}$ \\
\hline $1,070-1,075$ & $\begin{array}{c}56,13 \\
\left(40,0^{-73}, 0\right)\end{array}$ & $\begin{array}{l}13,05 \\
(5,79-18,55)\end{array}$ \\
\hline $1,080-1,085$ & $\begin{array}{c}64,27 \\
(46,5-85,0)\end{array}$ & $(6,30-18,5)$ \\
\hline $1,090-1,0.95$ & $\begin{array}{c}74,84 \\
(70,23-83,8)\end{array}$ & $\begin{array}{l}12,58 \\
(8,50-15,0)\end{array}$ \\
\hline $1,100-1,105$ & $\begin{array}{c}108,1 \\
(91,0-128,0)\end{array}$ & $\begin{array}{l}16,10 \\
(13,85-19,97)\end{array}$ \\
\hline
\end{tabular}

Valores médios - com variação entre parênteses. Adaptado de LE BLANC et alìi, 1986.

- A outra maneira ê administração intra-venosa de plasma de um doador selecionado, para potros mais velhos que já não têm capacidade intestinal de absorver macromoléculas. A dosagem $\vec{e}$ de 20. $\mathrm{ml}$ de plasma por $\mathrm{kg}$ de peso vivo, nessa dosagem um potro deve receber cerca de 1 litro de plasma e espera-se que a concentração de Ig circulante no potro chege a $30 \%$ da concentração do doador.

\subsection{Efeitos Deletérios Associados ao Processo}

E importante mencionar a incompatibilidade imunológica natural que pode ocasionalmente ocorrer no potro recëm-nascido. Essa condição, conhecida como doença hemolí- 
tica é causada pela absorção de hemaglutininas e hemolisinas do colostro da mãe sensibilizada. Acredita-se que a égua possa ser isoimunizada pela passagem transplacental de antígenos do feto herdados do garanhão, que a mãe não possui e por tanto não reconhece. O feto não é afetado no útero provavelmente devido ao tipo de placenta que representa uma barreira à passagem de anticorpos.

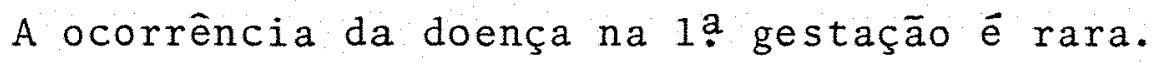
A maioria ocorre entre a 4a e 7 ạ gestação. Em algumas éguas os primeiros casos são brandos e subclínicos; isoimunização nas gestações subsequentes resulta em potros mais severamente afetados. No final da gestação ocorre um aumento do título de isoanticorpos no soro de êguas sensibilizadas; esse título cai rapidamente apôs o parto. Alto nível de isoanticorpos estā presente no colostro desses animais, embora um potro ativo possa reduzir o nível de 5: do original em 12 ho ras de vida.

Os potros parecem saudäveis nas primeiras horas de vida. De 8 horas a 5 dias os animais tornam-se progressivamente letärgicos, fracos e com mucosas pảlidas. Hả sinais de anemia aguda e severa devido à hemólise intravascu lar. Animais com menos de 3 dias que mostram sinais da doen ça são mais severamente afetados e morrem entre 24-36 horas, enquanto que potros mais velhos apresentam sintomas mais bran dos e podem se recuperar com manejo adequado.

Pode-se detectar isosensibilização na égua pe 
la técnica indireta de Coomb. Em casos suspeitos previne-se a doença evitando que o potro receba colostro da mãe entre 24 a 26 primeiras horas de vida. Diagnóstico em potros que ingeriram colostro é confirmado pelo teste direto de antiglobulina de Coomb para identificação de isoanticorpo nos eritröcitos do potro (FRANKS, 1962; JEFFCOTT, 1972).

RUMBAUGH et alii (1979) e LE BLANC et alii(1986) recomendam verificar a ausência de isoanticorpos no colostro e plasma armazenados para tratamento de animais com falha na transferência de imunidade.

As fêmeas podem tornar-se sensibilizadas a eri trócitos alogênicos por transfusão de sangue incompativel ou por passagem de eritrócitos fetais via placenta; nesse caso os anticorpos produzidos concentram-se no colostro. Equinos possuem 8 sistemas de grupos sanguíneos. O principal antígeno de grupo sanguíneo sensibilizante $\bar{e}$ o Aa seguido por $Q a, R$ e $S$.

O grau de sensibilidade materna aumenta com o nümero de gestações. O diagnóstico no potro $\vec{e}$ feito por adí ção de soro fresco de coelho (complemento), o que causa rápi da hemólise no caso de Aa e Qa. Se a doença for devida a $R$ e $S$ (menos antigênicos) sô é detectada por prova de antiimunoglobulina direta; na égua faz-se prova de anti Ig indireta com eritrócitos do garanhão. A procura de eritrócitos do potro contra o colostro da êgua ê de utilidade limitada, devido ao colostro induzir grande formação de "rouleaux", que mascara a aglutinação (TIZARD, 1985). 
Um outro efeito deletério associado é que a imunização ativa no potro jovem pode ser ineficaz se anticorpos maternos específicos estiverem presentes. Alexander e Mason ${ }^{1}$, citados em JEFFCOTT (1974a) demonstraram que a vacina viva contra "Doença Africana" (AHS) nāo tem efeito imuni$z$ ante em potros jovens cujas māes tenham anticorpos AHS circulantes. Vacinas de vírus vivo são inativadas por anticorpos que jā estejam em circulação antes que tenham chance de se multiplicar e exercer seu efeito antigênico.

\subsection{NutrigÃo X NíVEl IMUNOLGGico}

Estudos têm sido conduzidos para determinar o papel do consumo de energia, proteína, vitaminas Ee A, selênio e ferro na resposta imune de animais, principalmente em roedo res e suínos.

Com relação a mâ nutrição protéico-calörica GOOD \& LORENZ (1988) e KELLEY ६ EASTER (1987) comentam que seu efeito é bastante severo e que a imunodeficiência persiste mesmo após nu trição adequada.

1 ALEXANDER, R.A. \& J.H. MASON. Studies on neurotropic virus of Horse Sickness. VII Transmitted immunity. Ondersterpoort, J. Vet. Sci. Anim. Im., 16: 19-32, 1941. 
Consumo subótimo de Se em animais e humanos têm efeitos indesejâveis; entre esses hâ o efeito de impedir o desenvolvimento ou o funcionamento do sistema imune, comprometendo a resistência a infecçōes. O selênio juntamente com a vitamina E aumenta a capacidade de síntese de anticorpos, alêm de aumentar a proliferaçāo de linfôcitos T (COMBS \& COMBS, 1986; KELLEY \& EASTER, 1987). A suplementação com vitamina E favorece a resposta imune em bezerros (CIPRIANO et alii, 1982; REDDY et alii, 1986; REDDY et alii, 1987).

Sabe-se que a vitamina A e necessatria para a sintese de anticorpos, proliferação de linföcitos $T$, ativida de fagocitica das células polimorfanucleadas (BOON, 1987; KELLEY \& EASTER, 1987).

Em ratos deficientes em ferro, com anemia severa, constata-se uma redução da sintese proteica nos órgãos do sistema imune: baço, timo e fïgado, o que acarreta o com prometimento da resposta imune nesses animais (KELLEY \& EASTER, 1987; ROSCH et alii, 1987).

Outro aspecto interessante $\vec{e}$ apresentado pelo trabalho de PERDIGON et alii (1987), onde sāo fornecidas cul turas de bactërias (L. ocidophilus e S. thermophilus) a ratos, constatando-se um favorecimento da resposta imune nesses animais. Ambas as culturas de bactērias läticas aumenram significativamente a atividade fagocitôtica e enzimäti ca dos macrófagos peritoniais, alêm de acelerar a função fagocitótica do sistema reticuloendotelial. 


\section{MATERIAL E MÉTODOS}

\subsection{LOCAL}

A fase de campo deste trabalho foi realizada no Haras Rancho Nativo, município de Limeira, estado de São Paulo, a $130 \mathrm{Km}$ da capital, com ārea de 48,5 ha, situada a 542 metros de altitude. Localiza-se a $22^{\circ} 33^{\prime} 4^{\prime \prime}$ de latitude

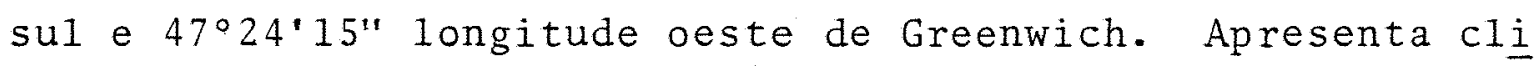
ma do tipo Cwa, segundo a classificação Kuppen, com precipitação média anual de $1353,5 \mathrm{~mm}$. As anālises laboratoriais rea lizaram-se no Laboratório de Fisiologia Animal do Departamen to de Zoologia da Escola Superior de Agricultura "Luiz de Queiroz".

\subsection{Animais}

Os animais que participaram deste experimento eram fêmeas das raças Mangalarga e Puro Sangue Inglês, re gistradas nos respectivos "Studbooks" e consideradas sadias 
por exame veterinärio rotineiro. Essas éguas foram escolh $\underline{i}$ das dentro de um plantel de 40 ëguas com base na data preví ta de parição. Participaram também os potros nascidos dessas éguas, desde a hora do nascimento ate 70 dias de idade.

Foram utilizadas 5 ëguas da raça Mangalarga e 5 éguas PSI para anälise do colostro à zero hora; 6 éguas Mangalarga e 7 PSI para amostragem de sangue; e 7 potros Ang1o-Arabes e 6 Mangalarga nascidos das fêmeas citadas anteriormente também para coleta de sangue.

A propriedade em questão não adota programa de vavinação de rotina, nem de emprego de medicamentos preventivamente.

\subsection{Amostragem de colostro}

Aproximadamente $30 \mathrm{ml}$ de colostro de cada égua foram coletados em frasco plâstico imediatamente após o par to, antes da primeira mamada e armazenado em geladeira até a data de anälise (só se consideraram vâlidas as análises feitas 2-3 dias após coleta, de acordo com PARRISH et alii (1950). 


\subsection{Amostragem de sangue}

As amostras de sangue foram retiradas da veia jugular, aproximadamente $10 \mathrm{~m} 1$ por animal. 0 material foi recebido em tubo de centrífuga, centrifugado e o soro resultante transferido para dois frascos devidamente identificados e armazenado a $-20^{\circ} \mathrm{C}$ ate a data da anâlise.

Diante da impossibilidade de se conhecer o dia exato de parição foram programadas cinco datas de amostragem para cada êgua gestante com base na data de cobertura, os resultados foram distribuídos nos períodos que se seguem: $3,9,16,23$ e mais de 26 dias antes do parto e na hora do parto, antes da 1 a mamada do potro.

A coleta de sangue dos potros obedeceu ao seguinte esquema: imediatamente pós-natal (antes de qualquer ingestão de colostro), 24 e 48 horas, $5,10,15,20,25,30$, $40,50,60$ e 70 dias apös o nascimento.

Para melhor controle da amostragem foi feita uma ficha de cada animal procurando abranger o maior número de informações possível para o trabalho. 0 modelo da ficha idealizado $\vec{e}$ o que se vê na Figura 2. 


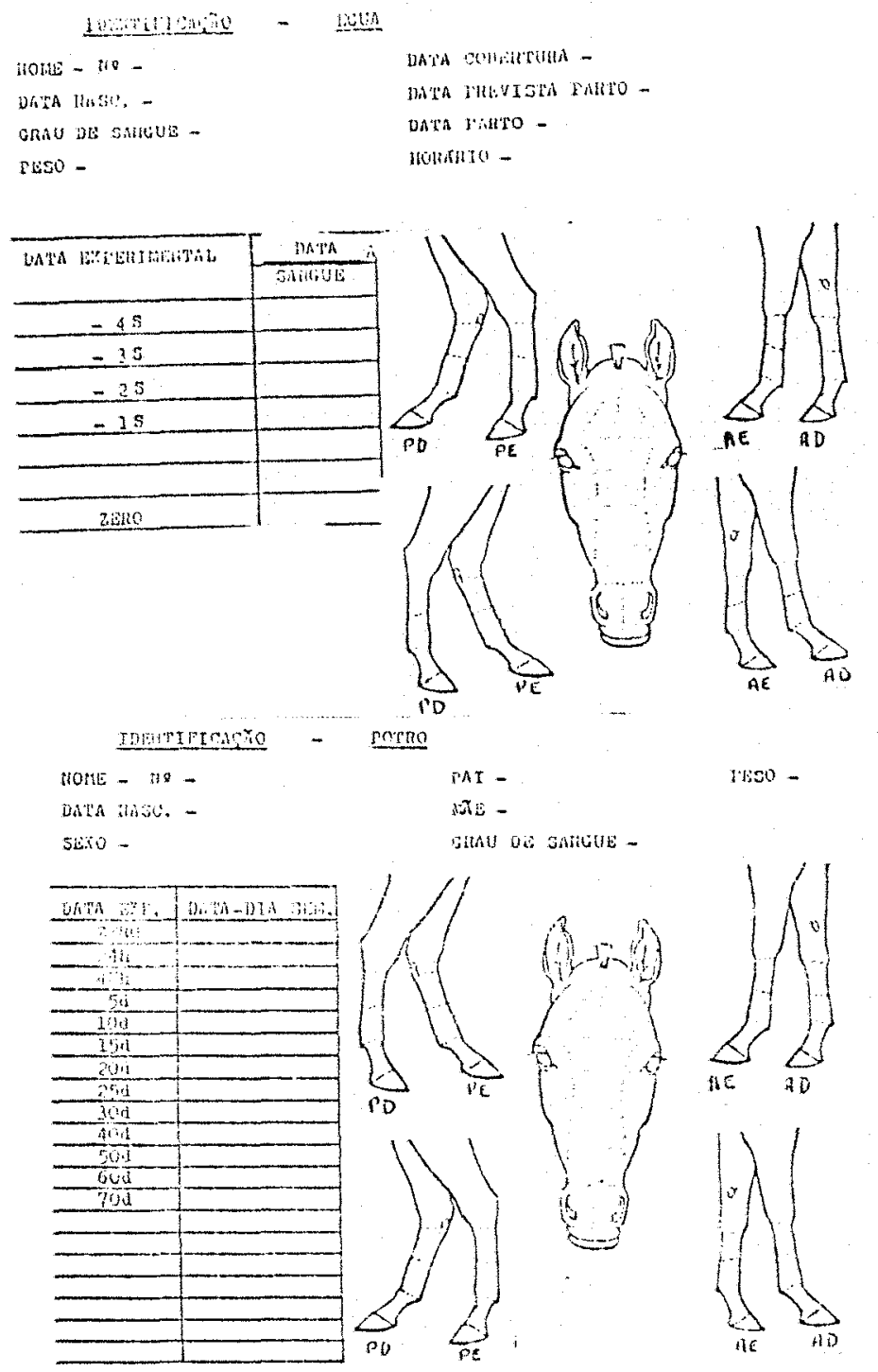

Figura 2. Ficha de controle de amostragem.

\subsection{AnAlise das amostras}

A IgG sërica das ëguas foi quantificada por imunodifusão radial, técnica descrita por MANCINI et alii 
(1965); 67 amostras foram analisadas. Para construção da curva padrão foi utilizada IgG obtida da Sigma Chemical Company - USA. O agar foi preparado com $0,8 \mathrm{~g}$ de agarose em 100 m1 de Tris-HC1 (pH $=8,0)$, solução mantida em ebulição até se tornar transparente, após o que permaneceu em banho - ma ria a $56^{\circ} \mathrm{C}$. Em cada placa colocou-se $5 \mathrm{ml}$ de agar e $125 \mathrm{ml}$ de anti-IgG (Sigma Chemical Company-USA). Procedeu-se a le $\underline{i}$ tura do diâmetro das reações após 48 horas, quando o cresci mento do precipitado cessou. A equação obtida foi:

$$
\begin{aligned}
& y=3,86 x-33,16, \text { onde } \\
& y=\text { concentração de IgG sérica em } \mathrm{mg} / \mathrm{m} 1 \\
& x=\text { diâmetro da reação }
\end{aligned}
$$

com coeficiente de correlação $r=0,98$.

A quantificação das Ig séricas dos potros baseou-se no método descrito por McEVAN et alii (1970) que se refere à leitura espectrofotomëtrica da turvação obtida da reação das imunoglobulinas com o sulfato de zinco, $2 \mathrm{nSO}_{4} \cdot 7 \mathrm{H}_{2} \mathrm{O}$. Preparou-se, a cada bateria de amostras, uma nova solução de sulfato de zinco com $208 \mathrm{mg}$ de $\mathrm{ZnSO}_{4} \cdot 7 \mathrm{H}_{2} \mathrm{O}$ em $1000 \mathrm{mI}$ de $\mathrm{H}_{2} \mathrm{O}$ destilada e mantida em ebulição por 20 minutos, para evitar a presença de $\mathrm{CO}_{2}$ que influencia a turvação e consequentemen te a densidade óptica. Todas as soluções utilizadas neste método foram mantidas livres de $\mathrm{CO}_{2}$. Para isso montou-se um sistema com tubos de lätex e pipetadores, de maneira que todo ar consumido na operação borbulhava em solução de $\mathrm{NaOH}$ an tes de entrar no circuito fechado. 
A temperatura, ambiente do laboratório foi estabilizada a $21^{\circ} \mathrm{C}$ durante as reações e leituras.

Procedeu-se à leitura da densidade óptica ou absorbância no espectrofotômetro (Coleman Junior II) em comprimento de onda de $660 \mathrm{~nm}$, após a adição de $100 \mu 1$ da amostra de soro a $6 \mathrm{ml}$ de $\mathrm{ZnSO}_{4} \cdot 7 \mathrm{H}_{2} \mathrm{O}$ e incubação por 60 minutos. Utilizaram-se unidades ZST (Zinc Sulfate Turbidity) para expressar a concentração de anticorpos séricos (densidade öptica X100). Para se estimar a concentração em mg de $I g / m l$ foi obtida uma curva padrão da densidade optica $X$ concentração de $\operatorname{Ig}(\mathrm{mg} / \mathrm{ml}$ ) obtida por imunodifusão radial da mesma forma descrita anteriormente, usando-se amostra de soro de 8 potros recêm-nascidos.

A equação resultante foi:

$y=84,04 x-0,87$, onde

$x=$ absorbância ou densidade óptica

$y=$ concentração de $\mathrm{Ig}$ em $\mathrm{mg} / \mathrm{mI}$,

com coeficiente de correlaçāo $r=0,88$.

A ocorrência de hemólise nas amostras implica em erro de leitura da turvação, variando com a intensidade da hemölise. A correçāo é dada pela fórmula (PFEIfFER, 1977):

$$
\text { [ ] Real Ig = 1eitura da turvação }-\left[A_{540} \times 23\right]
$$

onde:

[ ] ReaI Ig $=\mathrm{mg} / \mathrm{mI}$

Leitura da turvaçāo = absorbância em $660 \mathrm{~nm}$, convertida em $\mathrm{mg} / \mathrm{m} 1$; 
$\mathrm{A}_{540}=$ absorbância em $540 \mathrm{~nm}$ do soro com diluição 1:20.

Para corrigir os resultados obtidos em unidades ZST para hemólise, foi calculada a percentagem de correção resultante da förmula anteriormente descrita para dados em $\mathrm{mg} / \mathrm{ml}$.

O colostro foi analisado quanto à concentração de proteina total pelo método Micro-Kejeldah1, $N$ x 6,38. Con siderou-se que a concentraçāo de IgG do colostro correspondia a $40 \%$ da proteína total.

\subsection{Delineamento experimental}

Para anälise dos dados das éguas o delineamen to adotado foi o experimento inteiramente casualizado em par celas subdivididas, onde o período experimental foi considerado como sub-parcela. Foram considerados apenas 5 periodos experimentais porque para mais de 30 dias antes do parto não houve nümero de repetiçōes suficiente.

Para anâlise dos dados dos potros a relação entre o período de amostragem e unidades $2 S S^{*}$ foi estudada por diferentes modelos matemáticos. A cada ponto de amostra

\footnotetext{
* Unidades $\mathrm{ZST}=$ absorbância lida X100, indica concentração de IgG $(\mathrm{mg} / \mathrm{ml})$ no presente estudo.
} 
gem $(1,2,5, \ldots$ e 70 dias $)$ as concentrações de Ig sérica foram analisadas para estudar o efeito da raça de acordo com o modelo inteiramente casualizado com diferentes nümeros de re petiçōes.

A diferença de PT do colostro entre as duas raças foi analisada pelo teste "F" e as correlaçōes de interesse foram estabelecidas. 


\section{RESULTADOS E DISCUSSÃO}

Os dados originais provenientes das determinações de laboratório, para cada animal, são apresentados nos Apêndices de $n^{\circ} \mathrm{s} 1$ a 6 .

4.1. VARIAGÃo da IgG SÉrica em Éguas

Os níveis mëdios de IgG sêrica das éguas, nas diferentes determinações em relação ao dia do parto são apre sentados na Tabela 7. Diferenças ocorridas entre o dia esti mado da parição e o dia em que efetivamente ocorreu nos leva ram a agrupar as determinaçōes e apresentar o tempo mêdio decorrido em dias entre as determinaçōes e o parto. 
Tabela 7. Variação de IgG sérica (mg/m1 \pm EPM) em éguas Man galarga e PSI.

Períodos

(dias pré-parto)
Mangalarga

PSI

\begin{tabular}{rll}
0 & $26,1 \pm 1,8$ & $29,8 \pm 1,7$ \\
$3-6$ & $24,3 \pm 2,5$ & $30,7 \pm 1,7$ \\
$9-13$ & $21,7 \pm 2,4$ & $30,3 \pm 1,8$ \\
$16-20$ & $27,3 \pm 1,4$ & $28,5 \pm 0,9$ \\
$23-16$ & $25,3 \pm 1,9$ & $26,7 \pm 2,2$ \\
+ de 26 & $27,1 \pm 2,6$ & $25,6 \pm 3,4$ \\
\hline
\end{tabular}

A anālise de variância dos resultados revelou que a média de $28,95 \mathrm{mg} \operatorname{IgG} / \mathrm{m} 1$ de soro para éguas PSI é significativamente superior $(P<0,05)$ à mêdia de $24,17 \mathrm{mg} I \mathrm{gG} / \mathrm{ml}$ apresentada pelas éguas Mangalarga; por outro lado não se ve rificou interação significativa entre raça e período de amos tragem, de maneira que a flutuação sérica de IgG anterior ao parto não foi detectada, conforme ilustra a Tabela 8. 
Tabela 8. Análise da variância para estudo do efeito de raça e de período de amostragem na flutuação de IgG sérica em ëguas.

Causa da Variação

G.L.

S.Q.

Q.M.

F Níve1 :

Raça (RA)

Resíduo (a)

1

228,69

228,59

7,58 *

3,31

$6 \quad 180,88$

30,15

Parcelas

$7 \quad 409,47$

\begin{tabular}{lrrrrr}
\hline PEE x (PE) & 4 & 30,12 & 7,53 & $0,37 \mathrm{~ns}$ & 82,55 \\
Interação Raça x PE & 4 & 151,82 & 37,95 & $1,88 \mathrm{~ns}$ & 14,67 \\
Residuo (b) & 24 & 484,49 & 20,19 & & \\
\hline
\end{tabular}

TOTAL

$39 \quad 1075,91$

Vārios autores citados em JEFFCOTT

$(1974 a)$ mostraram que proteínas sêricas em vacas são continuamente incorporadas ao leite e as gamaglobulinas são preferencialmente concentradas pela glāndula mamäria; esse processo ê intensificado em estägios avançados de prenhez e leva a uma queda de proteina total e gamaglobulina sérica, OLIVEIRA et alii (1980b) sugerem o mesmo re sultado. O próprio JEFFCOTT (1974a) determinou essa queda en equinos: foi detectada uma queda definida de proteina e gamaglobulina antes e apös o parto que se iniciava 2 a 3 semanas antes, atin gindo o nive1 mais baixo 3 semanas apös o parto. A diferen- 
ça entre esses dados e os do presente trabalho pode estar no tempo de observação após a parição, maior para o referido autor, que observou durante 24 semanas antes e 24 semanas após o parto; ou ainda pode ser um efeito de raça (Jeffcott trabalhou com ëguas Poneyl, uma vez que as curvas obtidas pa ra as duas raças são bastante diferentes como se pode observar na Figura 3 .

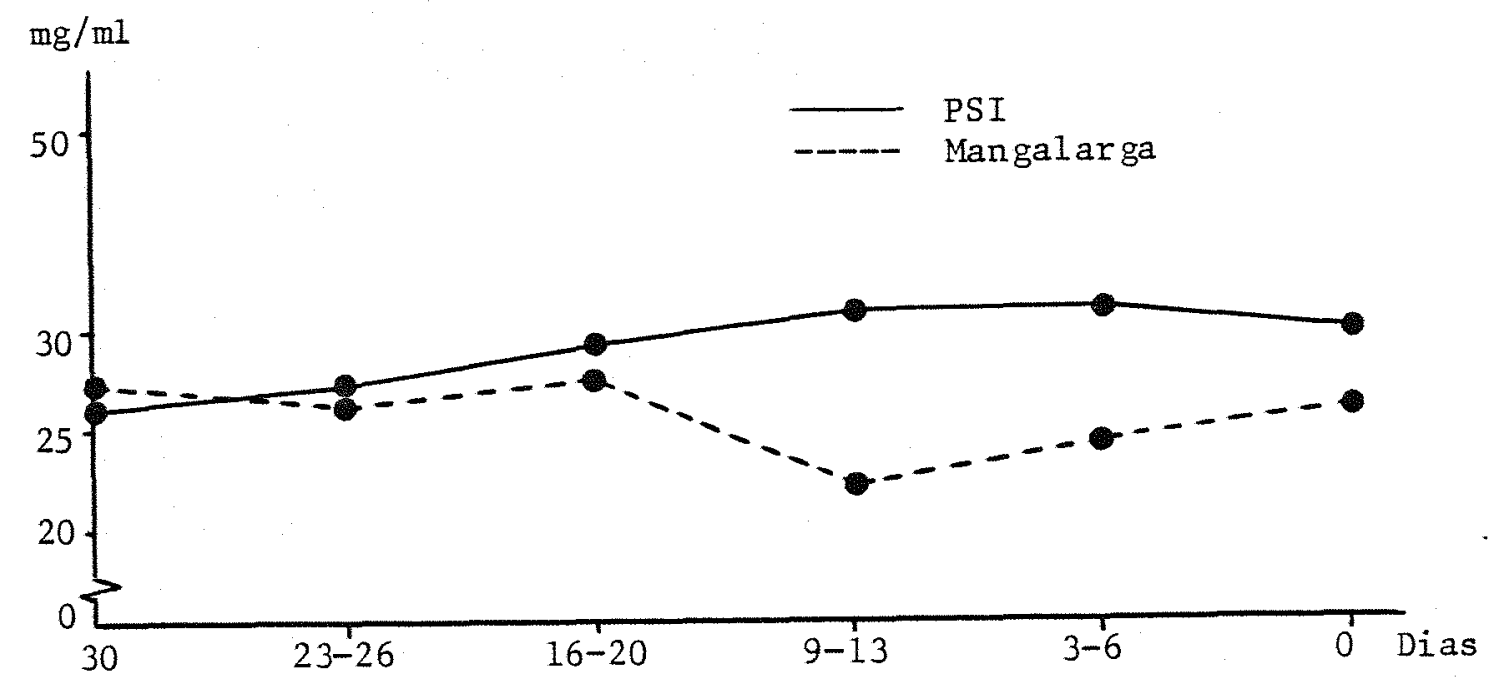

Figura 3. Variaçäo de IgG sêrica (mg/ml) em éguas das raças Mangalarga e PSI. 


\subsection{Proteina total do Colostro}

A média obtida para a concentração de PT no colostrou foi de $21,95^{\circ} \pm 0,90^{*}$ em éguas PSI significativamen te superior, segundo o teste "F" $(P<0,01)$, à média de $11,64 \%$ $\pm 2,95$ em ëguas Mangalarga (Tabe1a 9).

Tabela 9. Anâlise da variância para estudo do efeito de raça na PT do colostro de éguas.

Causas da Variação

G.L.

S.Q.

Q.M.

F Nivel :

Tratamentos

$1 \quad 265,74 \quad 265,74 \quad 11,12 * * \quad 1,031$

Residuo

8

191,15

28,39

TOTAL

$9 \quad 456,90$

o aspecto do material coletado era bastante diferente entre as duas raças, sendo o colostro das éguas PSI, com maior concentração de PT, de uma coloração amarela mais intensa e com maior viscosidade. LE BLANC et alii (1986) verificou que a maior viscosidade, que implica em maior gravidade especifica, se correlacionava positivamente com concentra ção de imunoglobulinas e ainda que a concentração de IgG sērica nos potros era mais alta quanto maior a concentra ção de IgG do colostro, o que concorda com o trabalho de Mac $: \pm E P M$ 
DOUGALL (1975) e com o presente trabalho como se verifica a seguir.

Determinada a PT do colostro, é possivel esti mar a concentração de IgG. Considerando-se IgG $(\mathrm{mg} / \mathrm{mg})=$ $40 \%$ PT do colostro (ROUSE \&. INGRAM, 1970) e a concentração de IgG sérica dos potros no pico de absorção (24-48 horas), obtida. neste estudo, teremos, Tabelas 10 e 11:

Tabela 10. Níveis de IgG do colostro de êguas PSI e de IgG sê rica em potros da raça Anglo-Arabe* no pico máximo de absorção.

$\begin{array}{ccc}N^{\circ} \text { animal } & \text { IgG colostro } \\ (\mathrm{mg} / \mathrm{ml})\end{array} \quad \mathrm{N}^{\circ}$ animal $\quad \begin{gathered}\text { IgG sërico } \\ (\mathrm{mg} / \mathrm{ml})\end{gathered}$

\begin{tabular}{lllll}
\hline $\mathrm{E}_{4}$ & 84,88 & $\mathrm{P}_{4}$ & 31,28 & $(24 \mathrm{~h})$ \\
$\mathrm{E}_{5}$ & 75,12 & $\mathrm{P}_{5}$ & 25,33 & $(24 \mathrm{~h})$ \\
$\mathrm{E}_{6}$ & 92,64 & $\mathrm{P}_{6}$ & 21,82 & $(5$ dias $)$ \\
$\mathrm{E}_{8}$ & 95,25 & $\mathrm{P}_{8}$ & 29,15 & $(48 \mathrm{~h})$ \\
$\mathrm{E}_{10}$ & 91,16 & $\mathrm{P}_{10}$ & 33,25 & $(24 \mathrm{~h})$ \\
\hline
\end{tabular}

* As éguas PSI utilizadas no presente estudo foram cruzadas com garanhões da raça Arabe, resultando em potros da raça Anglo-Arabe devidamente registrados no "Studbook". 
Tabela 11. Niveis de IgG do colostro e de IgG sérica em potros da raça Magalarga no pico máximo de absorção.

$N^{\circ}$ animal IgG colostro

( $\mathrm{mg} / \mathrm{mg})$
IgG sërica

№ animal

( $\mathrm{mg} / \mathrm{m} 1)$

\begin{tabular}{llll}
\hline$E_{1}$ & 31,44 & $P_{1}$ & $26,23(48 \mathrm{~h})$ \\
$E_{3}$ & 27,84 & $P_{3}$ & $15,52(24 \mathrm{~h})$ \\
$E_{7}$ & 35,92 & $P_{7}$ & $17,08(24 \mathrm{~h})$ \\
$E_{13}$ & 45,20 & $P_{13}$ & $17,62(48 \mathrm{~h})$ \\
$E_{14}$ & 92,44 & $P_{14}$ & $24,76(48 \mathrm{~h})$ \\
\hline
\end{tabular}

Com base nos câlculos anteriores temos mëdia de $87,8 \mathrm{mg}$ IgG/mg de colostro em éguas PSI superior $(\mathrm{P}<0,01)$ à mëdia de 46,57 mg IgG/mg em ëguas Mangalarga e consequentemente média de $28,17 \mathrm{mg} I g G / \mathrm{ml}$ de soro para potros Anglo-Âra bes no pico mäximo de absorção, superior ( $\mathrm{P}<0,01)$, segun do a anâlise de variância, à mêdia de $20,24 \mathrm{mg} I g G / \mathrm{m} 1$ de soro para potros Mangalarga (Tabe1a 12). 
Tabela 12. Anālise da variância para estudo do efeito de raça na concentração de IgG sêrica de potros no pon to de māxima absorção.

\begin{tabular}{lccccc}
\hline Causa da Variação & G.L. & S.Q. & Q.M. & F & Níve1 : \\
\hline Raça & 1 & 219,30 & 219,30 & $11,82^{* *}$ & 10,56 \\
Resíduo & 11 & 204,5 & 18,55 & & \\
\hline ToTAL & 12 & 403,35 & & & \\
\hline
\end{tabular}

A correlação entre a concentração de IgG no colostro e no sangue dos potros no pico máximo de absorção foi de $0,69(P<0,05)$.

De posse desses dados é possível tambëm calcu lar a eficiência de absorção de IgG do colostro pelos potros:

$$
\frac{\text { IgG sërica potro }}{\text { IgG colostro }} \cdot 100=: \text { de IgG absorvida }
$$

As eficiências mêdias de absorção foram $32,23 \%$ para potros Anglo-Arabes e 50,5\% para potros Mangalarga, cuja anälise de variância não revelou diferença estatística, indicando que o processo fisiológico de absorção foi semelhante para as duas raças neste estudo. 
Tabela 13. Anālise da variancia para estudo do efeito de raça na absorção do IgG do colostro pelos potros.

Causa da Variação $\quad$ G.L. $\quad$ S.Q. Q.M. $\quad$ F $\quad$ Nível :

\begin{tabular}{llrlll}
\hline Raça & 1 & 833,93 & 833,93 & $3,44 \mathrm{~ns}$ & 5,32 \\
Residuo & 8 & 1935,34 & 241,92 & & \\
\hline
\end{tabular}

TOTAL

$9 \quad 2769,27$

JEFFCOTT (1974c) trabalhando com potros e Mac Dougal1 (1972) ${ }^{1}$ citado em MacDougall (1975) com bezerros encontraram eficiências de absorção semelhantes, em torno de $50 \%$.

4.3. Imunoglobulinas SÉricas dos Potros

A Figura 4 ilustra os resultados obtidos com as observações dos potros.

1 Macdougall, D.T. The metabolism of plasma proteins in the young calf. Ph.D. Thesis, University of Glasgow, 1972. 
51.

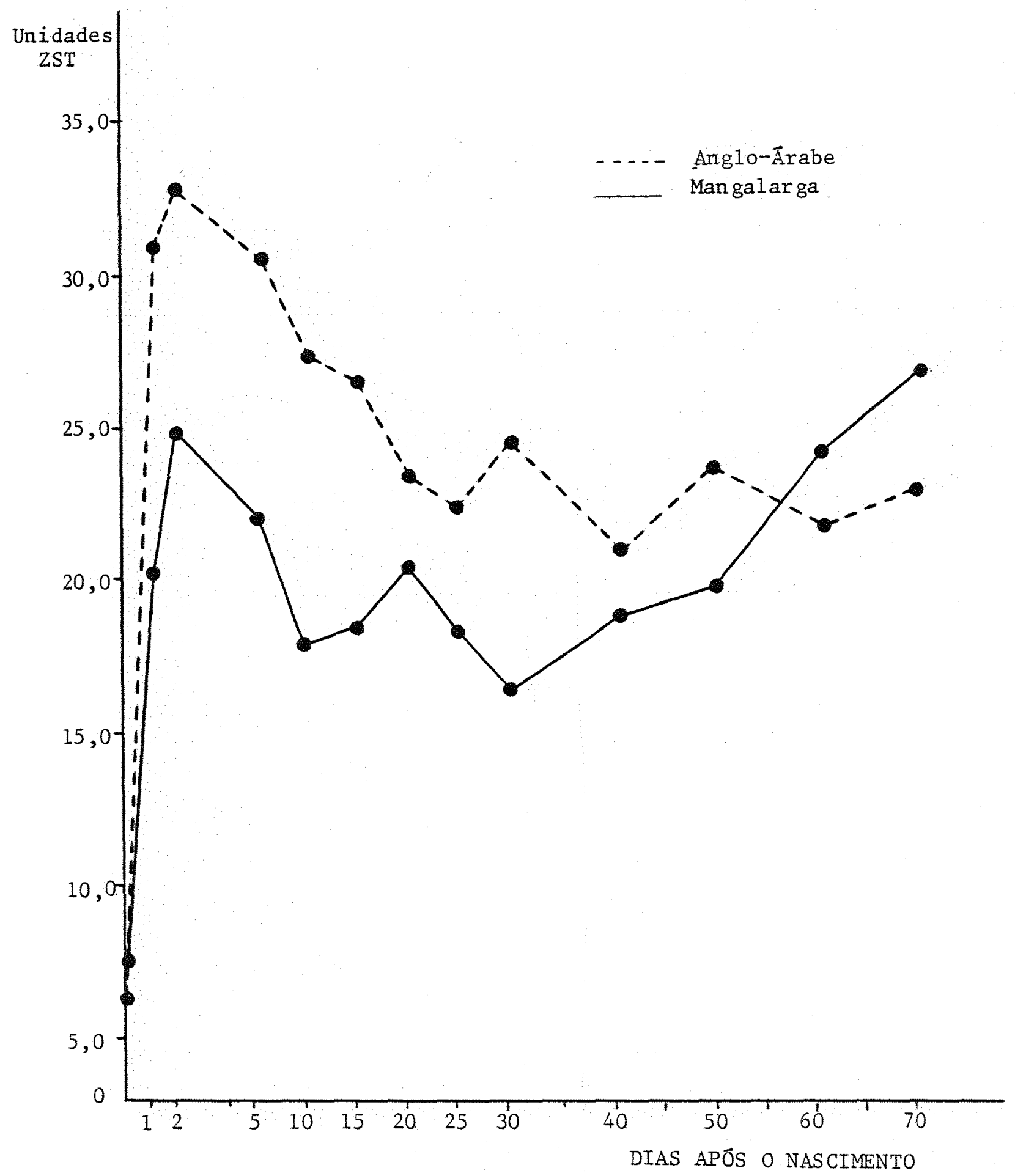

Figura 4. Variação da Ig sérica (unidades ZST) em potros das raças Mangalarga e Anglo-Arabe. 
Após as 48 horas, a relação entre período de coleta e unidades ZST, para a raça Mangalarga é expressa pelo modelo matemático:

$$
\begin{aligned}
& y=23,9274-0,39766 x+6,4675 \cdot 10^{-3} x^{2}, \text { onde } \\
& x=\text { período de coleta (dias) } \\
& y=\text { unidades } Z S T
\end{aligned}
$$

com $\quad \mathrm{r}=0,91$

$$
\mathrm{F}=20,3^{* *} \text {, }
$$

cuja estimativa do ponto de mínimo e 30,7 dias, coincidente com 0 ponto de inflexão (equação do $2^{\circ}$ grau), que pelos pontos observados, ocorre aos 30 dias. Na tentativa de discriminar os períodos experimentais, subdividiu-se omodelo 1 , resultando em dois novos modelos de regressão linear:

$$
\begin{aligned}
& y=23,1993-0,216542 x(2-30 \text { dias }), \text { onde } \\
& x=\text { periodo de coleta (dias) } \\
& y=\text { unidades } Z \text { ST }
\end{aligned}
$$

$$
\text { com } \quad \begin{aligned}
r & =-0,79 \\
F & =8,18^{*},
\end{aligned}
$$

- modelo para esse período indica uma queda significativa $(\mathrm{P}<0,05)$ de 0,2165 unidades 2 ST por dia atê $030^{\circ}$ dia, pon to minimo encontrado;

$$
\begin{aligned}
\mathrm{y} & =8,39883+0,260439 x(30-70 \text { dias }), \text { onde } \\
\mathrm{x} & =\text { periodo de coleta (dias) } \\
\mathrm{y} & =\text { unidades } \mathrm{ZST} \\
\mathrm{r} & =0,98 \\
\mathrm{~F} & =85,18 *
\end{aligned}
$$

indicando que aos 30 dias se inicia uma fase significativa $(\mathrm{P}<0,01)$ de aumento de 0,2604 unidades ZST por dia. Fisio- 
logicamente, o $1^{\circ}$ período $(2-30$ dias) revela o pico de con centração de IgG sérica adquirida passivamente às 48 horas de vida, o que corresponde à $80^{\circ}$ da concentração média de ani mais adultos, seguida de uma fase de catabolismo até os 30 dias, quando pode-se considerar o início da fase de produção endógena de IgG maior do que o catabolismo verificado no período anterior. A raça Mangalarga chega aos 70 dias com uma quantidade considerâvel de Ig sērica, atingindo $86 \%$ da concentração mëdia de IgG de animais adultos, ligeiramente supe rior à concentração mâxima de IgG passivamente adquirida até as 48 horas.

Para a raça Ang1o-Arabe a relaçāo entre o período de coleta e unidades ZST é expressa pelo mode10:

$$
\begin{aligned}
& y=34,161-0,756062 x+0,015604 x^{2}-1,013 \cdot 10^{-3} x^{3}, \text { onde } \\
& x=\text { periodo de coleta (dias) } \\
& y=\text { unidades ZST }
\end{aligned}
$$

com

$$
\begin{aligned}
& r=0,96, \\
& F=26,5^{*},
\end{aligned}
$$

que pode ser subdividido, a exemplo do modelo anterior em:

$$
\begin{aligned}
& y=31,563-0,0288999 x \quad(2-40 \text { dias), onde } \\
& x=\text { período de coleta (dias) } \\
& y=\text { unidades } Z \text { ST }
\end{aligned}
$$

$$
\text { com } \quad \begin{aligned}
\mathrm{r} & =-0,92 \\
\mathrm{~F} & =31,8677^{*}, \\
\mathrm{e} & =19,8672+0,0492596 \times \quad(40-70 \text { dias }), \text { onde } \\
\mathrm{x} & =\text { período de coleta (dias) } \\
\mathrm{y} & =\text { unidades } 2 \mathrm{ST} \\
\mathrm{r} & =0,50 \\
\mathrm{~F} & =0,65 \mathrm{~ns},
\end{aligned}
$$


as regressões acima indicam um ponto de minimo de 39 dias até o qual o modelo $2 \mathrm{~A}$ revela uma queda significativa $(\mathrm{P}<0,05)$ de 0,2890 unidades ZST por dia, e um ponto de inflexāo de 51 dias, diferente e posterior ao ponto de mînimo (equação do $3^{\circ}$ grau). O modelo $2 \mathrm{~B}$ indica que após os 40 dias o acrêscimo de unidades ZST não é significativo e atê os 70 dias ainda não se observa uma relação linear entre as duas variảveis. Fisiologicamen te revela-se uma fase de catabolismo das IgG dos 2 aos 40 dias, após o que pode-se considerar o início da fase de produção endógena, uma vez que a concentraçāo permanece pratica mente constante atê os 51 dias (ponto de inflexão da curva) quando observa-se uma tendência de ascenção da curva. 0 nível de Ig em Ang 10-Arabes atinge, aos 70 dias, 65: da concentração de IgG sérica mêdia de animais adultos, quantidade inferior à concentração máxima de IgG passivamente adquirida, que chega às 48 horas, a $93 \%$ da concentração do adulto às 48 horas.

O histograma da Figura 5 ilustra essas consideraçōes.

E provảvel que a alta concentração de IgG materna presente na circulação dos potros Anglo-Árabes às 48 ho ras retarde $o$ início da fase endógena de produção de anticor pos em comparaçāo com os potros da raça Mangalarga, que apre sentaram dentro do período observado uma fase de aumento da concentração de IgG sêrica que não pode ser atribuída à absor ção de imunoglobulinas do colostro. Esses resultados concordam com os trabalhos de PORTER (1979), RIBEIRO et alii (1983) e MACHADO NETO \& PACKER (1986). Embora os potros Anglo-Arabes ainda tenham um nivel sêrico mëdio de IgG superior aos Manga- 
larga dentro do período observado, inclusive às 48 horas ( $\mathrm{p} \underline{i}$ co de absorção), aos 70 dias de idade o nível sérico de Ig dos potros Mangalarga foi superior aos dos potros Ang10-Arabes.
Egua Mangalarga Adulta - $25,3 \mathrm{mg} \mathrm{IgG} / \mathrm{ml}$
Potro Mangalarga - 48 horas - $20,2 \mathrm{mg} \mathrm{IgG} / \mathrm{ml}$
$\square$ Potro Mangalarga - 70 dias - $21,7 \mathrm{mg} \mathrm{Ig} / \mathrm{ml}$
目 Égua PSI adulta $-28,6 \mathrm{mg} \mathrm{IgG} / \mathrm{ml}$
图 Potro AA - 48 horas - $26,7 \mathrm{mg} I \mathrm{gG} / \mathrm{m} 1$
䧃 Potro AA - 70 dias - $18,6 \mathrm{mg} \mathrm{Ig/ml}$

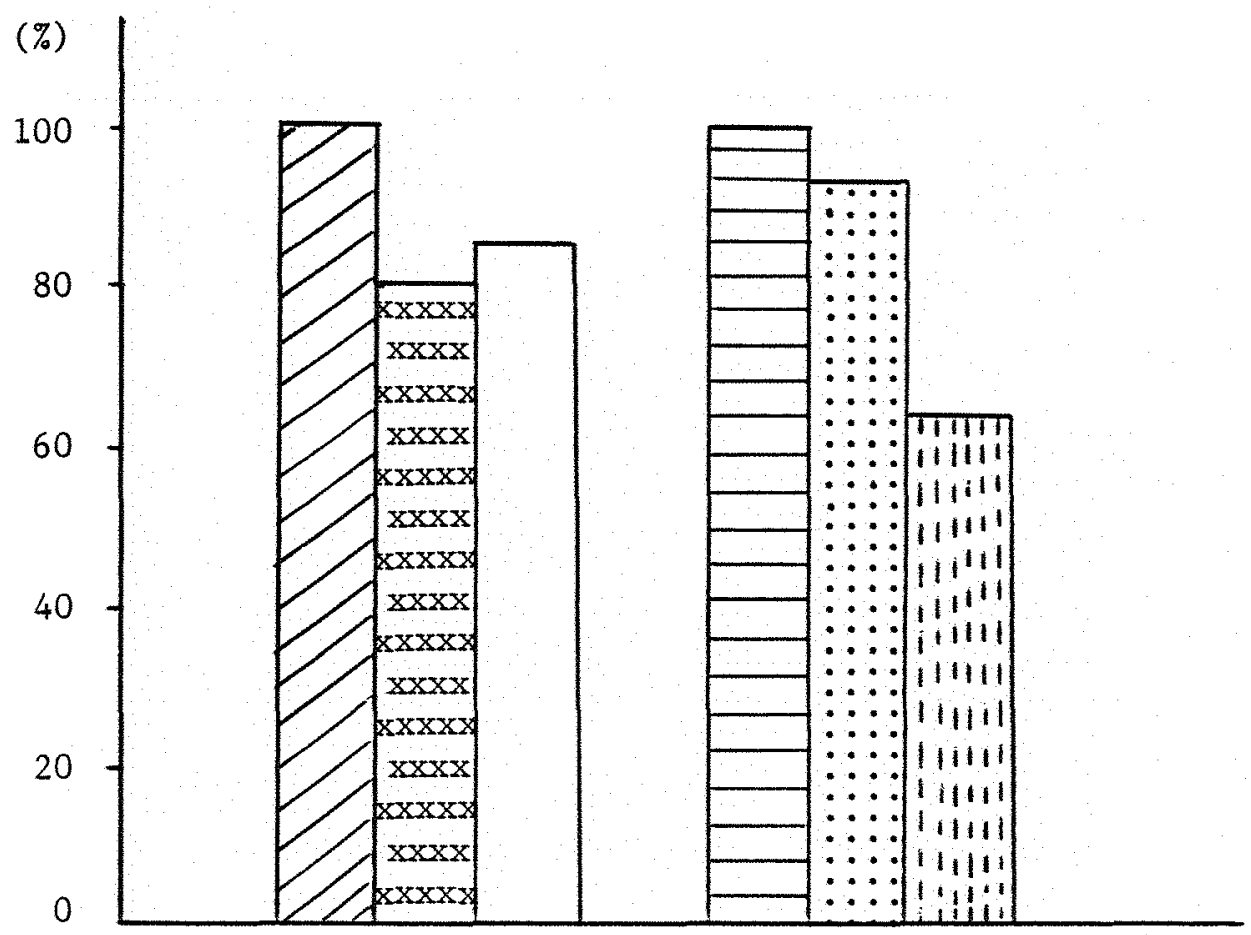

Figura 5. Comparação do nível de Ig sêrica de potros com o nivel médio de adulto. 
Outra interpretação para esta situação poderia ser que a ausência de acréscimo significativo após o ponto de menor concentração encontrado para os potros Anglo - Arabes tenha representado a interação dos processos de catabolismo das Ig absorvidas e de produção endógena de Ig, de maneira que não foi possivel caracterizar o ponto de inflexão da curva e, consequentemente, o início da fase endógena no período observado.

Observando a Tabela 14 verifica-se que a concentraçāo de IgG sérica de potros PSI se mantēm significativamente superior à concentração de potros Mangalarga até os 10 dias, período onde a variação da concentraçāo sérica de IgG e exclusivamente devida à IgG exógena, proveniente do colostro. Aos trinta dias, epoca em que se caracteriza o início da fase de produção de Ig endógenas na raça Mangalar ga, a concentração de Ig dessa raça se mantêm significativa mente inferior, quadro que se inverte aos 70 dias, quando a concentração de Ig sêrica dos Mangalarga estā em ascenção e passa a ser significativamente superior, enquanto que nos po tros AA o catabolismo da IgG exógena e a produção de Ig en dögenas se equivalem, adiando a caracterização da fase de pro dução.

Ainda é possível observar que o coeficiente de variaçāo (CV) tende a se reduzir nos períodos mais avançados de amostragem, indicando que ha um menor numero de variáveis envolvidas na fase endógena de produção de Ig. 
Tabela 14. Anālise da variância para estudo do efeito de raça na concentração de Ig sërica de potros nos diferentes pontos de amostragem.

\begin{tabular}{|c|c|c|c|c|c|c|c|}
\hline \multirow{2}{*}{ Causa da } & \multirow{2}{*}{ Variação } & \multirow{2}{*}{ GL } & \multirow{2}{*}{$\mathrm{QM}$} & \multirow{2}{*}{ PROB } & \multirow{2}{*}{$\mathrm{CV}(:)$} & \multicolumn{2}{|c|}{ Mëdias $(\mathrm{mg} / \mathrm{ml})$} \\
\hline & & & & & & $\mathrm{AA}$ & ML \\
\hline 1 dia & $\begin{array}{l}\text { Raça } \\
\text { Resíduo }\end{array}$ & $\begin{array}{l}1 \\
9\end{array}$ & $\begin{array}{r}309,82 \\
78,23\end{array}$ & 0,07 & 33,87 & $\begin{array}{l}30,96 \\
26,50\end{array}$ & $\begin{array}{l}20,23 \\
17,77\end{array}$ \\
\hline 2 dias & $\begin{array}{l}\text { Raça } \\
\text { Resíduo }\end{array}$ & $\frac{1}{7}$ & $\begin{array}{r}126,67 \\
34,65\end{array}$ & 0,09 & 21,25 & $\begin{array}{l}33,00 \\
26,78\end{array}$ & $\begin{array}{l}25,04 \\
20,18\end{array}$ \\
\hline 5 dias & $\begin{array}{l}\text { Raça } \\
\text { Residuo }\end{array}$ & $\begin{array}{l}1 \\
9\end{array}$ & $\begin{array}{r}202,88 \\
15,00\end{array}$ & 0,005 & 14,86 & $\begin{array}{l}30,63 \\
24,87\end{array}$ & $\begin{array}{l}22,00 \\
17,62\end{array}$ \\
\hline 10 dias & $\begin{array}{l}\text { Raça } \\
\text { Residuo }\end{array}$ & $\begin{array}{l}1 \\
9\end{array}$ & $\begin{array}{r}240,55 \\
13,11\end{array}$ & 0,002 & 15,56 & $\begin{array}{r}27,54 \\
28,78\end{array}$ & $\begin{array}{l}18,15 \\
14,39\end{array}$ \\
\hline 15 dias & $\begin{array}{l}\text { Raça } \\
\text { Residuo }\end{array}$ & $\begin{array}{l}1 \\
8\end{array}$ & $\begin{array}{r}174,31 \\
53,09\end{array}$ & 0,10 & 32,13 & $\begin{array}{l}26,00 \\
20,94\end{array}$ & $\begin{array}{l}18,50 \\
14,68\end{array}$ \\
\hline 20 dias & $\begin{array}{l}\text { Raça } \\
\text { Residuo }\end{array}$ & $\begin{array}{l}1 \\
9\end{array}$ & $\begin{array}{l}29,40 \\
43,54\end{array}$ & 0,56 & 28,87 & $\begin{array}{l}23,58 \\
18,95\end{array}$ & $\begin{array}{l}20,30 \\
16,19\end{array}$ \\
\hline 25 dias & $\begin{array}{l}\text { Raça } \\
\text { Residduo }\end{array}$ & $\begin{array}{r}1 \\
10\end{array}$ & $\begin{array}{l}44,85 \\
31,15\end{array}$ & 0,25 & 26,66 & $\begin{array}{l}22,57 \\
18,10\end{array}$ & $\begin{array}{l}18,65 \\
14,80\end{array}$ \\
\hline 30 dias & $\begin{array}{l}\text { Raça } \\
\text { Residuo }\end{array}$ & $\begin{array}{l}1 \\
9\end{array}$ & $\begin{array}{r}186,37 \\
15,50\end{array}$ & 0,007 & 19,36 & $\begin{array}{l}24,00 \\
19,34\end{array}$ & $\begin{array}{l}16,58 \\
13,07\end{array}$ \\
\hline 40 dias & $\begin{array}{l}\text { Raça } \\
\text { Resíduo }\end{array}$ & $\begin{array}{r}1 \\
10\end{array}$ & $\begin{array}{r}9,98 \\
10,73\end{array}$ & 0,64 & 16,19 & $\begin{array}{l}21,00 \\
16,78\end{array}$ & $\begin{array}{l}19,15 \\
15,23\end{array}$ \\
\hline 50 dias & $\begin{array}{l}\text { Raça } \\
\text { Resíduo }\end{array}$ & $\begin{array}{r}1 \\
11\end{array}$ & $\begin{array}{r}48,81 \\
107,77\end{array}$ & 0,04 & 14,14 & $\begin{array}{l}23,93 \\
19,24\end{array}$ & $\begin{array}{l}20,04 \\
15,98\end{array}$ \\
\hline 60 dias & $\begin{array}{l}\text { Raça } \\
\text { Resíduo }\end{array}$ & $\begin{array}{r}1 \\
10\end{array}$ & $\begin{array}{l}13,60 \\
19,32\end{array}$ & 0,60 & 18,06 & $\begin{array}{l}22,29 \\
17,75\end{array}$ & $\begin{array}{l}24,30 \\
19,53\end{array}$ \\
\hline 70 dias & $\begin{array}{l}\text { Raça } \\
\text { Resíduo }\end{array}$ & $\frac{1}{11}$ & $\begin{array}{r}46,44 \\
6,76\end{array}$ & 0,02 & 10,40 & $\begin{array}{l}23,32 \\
18,66\end{array}$ & $\begin{array}{l}27,13 \\
21,85\end{array}$ \\
\hline
\end{tabular}

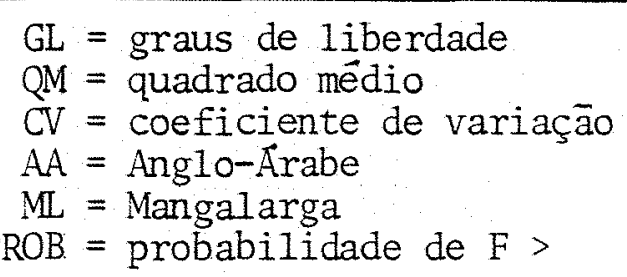




\section{CONCLUSÕES}

Os resultados desse trabalho permitiram estabelecer as seguintes conclusões:

1. Apesar de nāo ter sido detectada queda sig nificativa de IgG sérica nas éguas no período pré-parto, fato considerado normal em função da concentração de IgG pela glândula mamäria para produção de colostro, a transferência de imunidade passiva da mãe para o recëm-nascido via colostro ocorreu eficientemente.

2. A concentração mëdia de IgG sêrica em éguas PSI foi significativamente superior $(P<0,05)$ à concentração em ëguas Mangalarga.

3. A concentraçāo média de PT e, consequentemente, de IgG estimada do colostro de éguas PSI foi significativamente superior $(P<0,01)$ à concentração de PT em éguas Mangalarga.

4. A cor amarelada e a viscosidade do colostro estiveram associadas à concentraçāo de PT e consequentemente de IgG. 
5. Q quantidade estimada de IgG no colostro apresentou alta correlação com a concentração sërica de IgG nos potros no pico de máxima absorção $(\mathrm{P}<0,05)$.

6. A maior quantidade de IgG passiva presente no sangue de potros Ang10-Arabes nos primeiros dias determinou o retardamento no estabelecimento dos níveis normais de Ig.

7. Sob as mesmas condiçōes de desafio imunoló gico, animais com menor concentraçāo de IgG passiva apresen taram resposta mais intensa, como a que se observou com os potros Mangalarga. 


\section{REFERENNCIAS BIBLIOGRĀFICAS}

ARGENZIO, A. Digestão, absorção e metabolismo. In: SWENSON, M.J. Duke's physiology of domestic animals. 10a ed, Ithaca, 1984, cap. 3, p.263-4.

ASSOCIATION OF OFFICIAL ANALYTICAL CHEMISTS, Washington, DC. Official methods of analysis of the AOAC, Wasinington, DC, $1980,1010 \mathrm{p}$.

BIERER, B.W. Electrophoretic analysis of blood serum and plasma proteins of normal horses. Am. J. Vet. Res., Chicago, 30(12): 2237-40, dez. 1969.

BOON, P.C. Simposium: immune function: relationship of nutrition and disease control. J. Dairy Sci., Champaigne, 70: $27-32-43,1987$.

BOYD, J.W. The relationship between serum immune globuline deficiency and disease in calves: a farm survey. Vet. Rec., London, $90(23): 645-49$, jun. 1972 .

BRAMBELL, J.W.R. The passive immunity of the young mammal. Biol. Rev., Cambridge, 33: 488-531, 1958.

BRUNER, D.W.; P.R: EDWARDS; E.R. DOLL. Passive immunity in the newborn foal. Cornel1 Vet., I thaca, 38: 363-66, 1948. 
BUENING, G.M.; L.E. PERRYMAN; T.C. McGUIRE. Practical methods of determining serum immunoglobulin $M$ and immunoglobulin $G$ concentrations in foals. J.A.V.M.A., Chicago, 171(5): 455-58, set. 1977 .

CIPRIANO, D.E.; J.L. MORRILL; N.V. ANDERSON. Effect of dietary vitamin $E$ on immune responses of calves. J. Dairy Sci, Champaigne, 65: 2357-65, 1982 .

COMBS Jr., G.F. \& S.B. COMBS. The role of selenium in nutrition. Academic Press, Inc. New York, 532p., 1986.

EARLE, J.P. Influence of the ingestion of colustrum on pro teins of the blood sera of young foals, kids, lambs, and pigs. J.Agr. Res., Washington, DC, $\underline{51}(6)$ : 479-91, set. 1935 .

FRANKS, D. Horse blood groups and hemolytic disease of the newborn. Annals New York Academy of Sciences, New York, 97: $235-50,1962$.

GOOD, R.A. \& E. LORENZ. Nutrition, immunity, aging and cancer. Nutrition Reviews, New York, 46(2): 62-7, 1988.

HARPER, H.A. Química fisiolögica. Trad. Silvio Bevilaqua, Atheneu Editora S.A., São Paulo, 1958. 533p.

JEFFCOTT, L.B. Duration of permeability of the intestine to macromolecules in the newly-born foal. Veterinary Record, London, 88(13): 340-41, mar. 1971 .

JEFFCOTT, L.B. Passive immunity and its transfer with special reference to the horse. Biol. Rev., Cambridge, 47: $439-64, \quad 1972$. 
JEFFCOTT, L.B. Some practical aspects of the transfer of Passive Immunity to newborn foals. Equine Veterinary Jour na1, London, $\underline{6}(3): 105-15$, ju1. 1974a.

JEFFCOTT, L.B. Studies on passive immunity in the foal. J. Comp. Path. Ther.. 84: 93-101, 1974 b.

JEFFCOTT, L.B. Studies on passive immunity in the foal. II. The absorption of $125 \mathrm{I}-1$ abelled PVP (polyvimil parolidone) by the neonatal intestine. J. Comp. Path. Ther., 84 : 1$11,1974 \mathrm{C}$.

JEFFCOTT, L.B. The transfer of passive immunity to the foal and its relation to immune status after birth. J. Reprod. Fert., Oxford, 23: $727-33,1975$.

KELLEY, K. \& R. EASTER. Nutritional factors can influence immune response of swine. Feedstuffs, Minnetonka, $\underline{6}$ : 1417 , jun. 1987.

KENT, J.E. \& D.S. BLACKMORE. Measurement of IgG in equine blood by immunoturbidimetry and latex agglutination. Equi ne Veterinary Journa1, London, 17(2): 125-29, 1985.

LE BLANC, M.M.; B.I. MCLAURIN; R. BOSWELL. Relationship among serum immunoglobulin concentration in foals, colostral specific gravity and colostral immunoglobulin concentration. J.A.V.M.A., Chicago, $189(1):$ jul. 1986.

MacDOUGALL, D.F. Immunoglobulin metabolism in the neonatal foal. J. Reprod. Fert., Oxford, 23: 739-42, 1975. 
MACHADO NETO, R. \& I.U. PACKER. Flutuação de imunoglobulina sérica em bezerros da raça hol andesa submetidos a diferen tes regimes de aproveitamento. Revista da Sociedade Brasileira de Zootecnia, Viçosa, 15(5): 439-47, 1986.

MANCINI, G.; A.O. CARBONARA; J.E. HEREMANS. Immunochemical quantification of antigens by single radial immodifusion. Immunoch., London, 2: 235-254, 1965.

MCEVAN, A.D.; E.W. FISHER; I.E. SELMAN; W.J. PENHALE. A tur bidity test for the estimation of immunoglobulin levels in neonatal calf serum. Clin. Chem. Acta, Amsterdam, 27: $155-63, \quad 1970$.

MCGUIRE, T.C. \& T.B. CRAWFORD. Passive immunity in the foal: Measurement of immunoglobulin classes and specific antibody. Am. Vet. Res., Chicago, 34 (10): 1299-303, out. 1973.

MCGUIRE, T.C.; M.J. POPPIE; K.L. BANKS. Hypogammaglobulinemia predisposing to infection in foals. J.A.V.M.A., Chicago, $166(1): 71-5, j$ an. 1275 .

MCGUIRE, T.C.; T.B. CRAWFORD; A.L. HALLWELL; L.E. MACOMBER. Failure of colotral immunoglobulin transfer as on explanation for most infections and deaths of neonatal foals. J.A.V.M.A., Chicago, 170(11): 1302-04, jun. 1977 .

MORRIS, I.G. Gammaglobuline absorption in the newborn. In: CODE, C.F. Handbook of physiology alimentary canal. American Physiological Society. Baltimore, 3: 1491-512, 1968.

OLIVEIRA, F.R.A.P. de; F. GACEK; L. CURY; C. AUGUSTO; J.F.S. LEAO. Evolução do perfil soro protéico em asininos e muares durante o desenvolvimento. Bol. Ind. Animal, Nova Odessa, $37(2): 245-56,1980 a$. 
OLIVEIRA. F.R.A.P. de; F. GACEK; J.F.S. LEAO; J.M. VIEIRA; C. AUGUSTO. Perfil das globulinas do soro sanguineo, durante a gestação na jumenta. Bol. Ind. Animal, Nova odes sa, $\underline{40}(2): 219-27,1983$.

PARRISH, D.B.; G.H. WISE; J.S. HUGHES; F.W. ATKESON. Properties of the colostrum of the dairy cow. V. Yield, specific gravity and concentrations of total solids and its various components of colostrum and early milk. J. Dairy Sci., Campaigne, $\underline{3} 3(6): 457-65,1950$.

PEARSON, R.C.; A.L. HALLOWELL; W.M. BAYLY; R.L. TORBECK; L.E. PERRYMAN. Times of apearance and disepearance of colostral IgG in the mare. Am. J. Vet. Res., Chicago, $45(1)$ : 186-190, jan. 1984 .

PEMBERTON, D.H.; K.W. THOMAS; M.J. TERRY. Hypogammaglobulinemia in foals: prevalence on Victoria studs and simple methods for detection and correction in the field. Aust. Vet. J., Sidney, 56: 462-73, 1980 .

PERDIGON, G.; MACIAS, M.E.N.; ALVAREZ, S.; OLIVER, G.; HOLGADO, A.A.P.R. Enhancement of immune response in mice fed with Streptococcus thermophilus and Lactobacillus aci dophilus. J. Dairy Sci., Champaigne, 70: 219-26, 1987.

PFEIFFER, N.E. \& T.C. MCGUIRE. A sodium-sulfite precipitation test for assessment of colostral immunoglobulin trans fer to calves. J.A.V.M.A., Chicago, 170(8): 809-11, abr. 1977a.

PFEIfFER, N.E.; T.CW. MCGUIRE, R.B. BELDEL; J.M. WEIKEL. Quantitation of bovine immunoglobulin: comparison of single radial immunodifusion, zinc sulfate turbidity, serum, electrophoresis and refractometer methods. Am. J. Ve. Res., Chicago, 38(5): 693-98, $1977 \mathrm{~b}$.

PLATT, H. Septicemia in the foal. Br. Vet. J., London, 129: $221-29, \quad 1273$. 
POPPIE, M.J. \& T.C. MCGUIRE. Combined immunodeficiency with failure of colostral immunoglobulins transfer in foals. Vet. Rec.: London, 99: 44-6, ju1. 1976.

PORTER, P. Adoptive immunization of the neonate by breast factors. In: OGRA, P.L. \& D. DAYTON. Immunology of Breast Milk. New York, Raven Press, p.197-206, 1979.

REDDY, P.G.; J.L. MORRILL; H.C. MINOCHA; M.B. MORRILL, A.D. ; DAYTON, R.A. FREY. Effect of supplemental vitamin $E$ on the immune system of calves. J. Dairy Sci., Champaigne, 69: $164-171,1986$.

REDDY, P.G.; J.L. MORRILL; H.C. MINOCHA; J.S. STEVENSON. Vitamin $\mathrm{E}$ is immunostimulatory in calves. J. Dairy Sci., Champaigne, $70: 993-9,1987$.

RIBEIRO, M.F.M. ; P.A.D. BELEM; J.H. PARROYO, S.; J.F. DE FARIA. Hipogamaglobulinemia em bezerros. Arq. Bras. Med. Vet. Zoot., Belo Horizonte, $35(4): 537-546,19$.

ROITT, I. Essencial immunology. 3a ed., Blackwell Scientific Publications, Oxford, 1877 . $324 \mathrm{p}$.

ROSCH, L.M.; A.R. SHERMAN; D.K. LAYMAN. Iron deficiency impairs protein synthesis in immune tissues of rat pups. J. Nutr., Filadë1fia, 117: 1475-81, abr. 1987 .

ROUSE, B.T. E D.G. INGRAM. The total protein and immunoglobulin profile of equine colostrum and milk. Immunology, Oxford, 19: $901-907,1970$.

ROUSE, B.T. The immunoglobulins of adult equine and foal sera: a quantitative study. Br. Bet. J., London, 127 : 45-52, 1971. 
RUMBAUGH, G.E.; A.A. ARDANS; D. GUNNO; A. TROMMERSHAUSEN-SMITH Measurement of neonatal equine immunoglobulins for asses ment of colostral immunoglobulin transfer: comparison of single radial immunodiffision with the zinc sulfate turbidity test, serum electrophoresis, refractometry for total serum protein and the sodium sulfite precipitationtest. J.A.V.M.A., Chicago, 172(3): 321-25, fev. 1978.

RUMBAUGH, G.E.; A.A. ARDANS; D. GINNO; A. TROMMERSHAUSEN-SMITH. Identification and treatment of colostrum-deficient foals. J.A.V.M.A., Chicago, $174(3): 273-76$, fev. 1979 .

SCHMIDT, G.W. Biology of Lactation. São Francisco, G.W. SA LISBURY, $1971.317 \mathrm{p}$.

SIMPSON-MORGAN, M.W. \& T.C. SMEATON. The transfer of antibodies by neonates and adults. Adv. Vet. Sci. Comp Med., New York, 16: 355-83, 1972.

TEMPLETON, J.W.; R. SMITH III; G. ADAMS. Natural disease resistance in domestic animals. J.A.V.M.A., Chicago, 192 (9) : 1306-15, mai. 1988.

TIZARD, I. Imunologia Veterināria. Trad. da $2 a$ ed. america na, Livraria Roca Ltda., São Paulo, 1985. 329p.

TOWNSEND, H.G.G.; H. TABEL; F.M. BRISTOL. Induction of parturation in mares: effect on passive transfer of immunity to foals. J.A.M.V.A., Chicago, 182(3): 255-57, fev. 1983 .

ULLREY, D.E.; R.D. STRUTHERS; D.G. HENDRICKS; B.E. BRENT. Com position of mare's milk. J.Anim. Sci., Champaigne, 25: 211-22, 1966. 
WATSON, D.L.; M.A. BENNETT; J.R. GRIFFITHS. A rapid specific test for detecting absorption of colostral IgG by the neonatal foal. Aust. Vet. J., Sidney, 56: 513-16, 1980. 
68.

A $\underline{\mathrm{P}} \underline{\mathrm{E}} \underline{\mathrm{N}} \underline{\mathrm{I}} \underline{\mathrm{C}} \underline{\mathrm{E}} \underline{\mathrm{S}}$ 
Apêndice 1. Determinaçōes individuais da $\operatorname{IgG}$ sêrica (mg/ml) de ëguas PSI dias antes do parto.

\begin{tabular}{lllllll}
\hline $\begin{array}{c}\text { Epoca de } \\
\text { amostragem }\end{array}$ & Parto & $3-6$ & $9-13$ & $16-20$ & $23-26$ & + de 26 \\
$\begin{array}{c}\text { No do } \\
\text { anima1 }\end{array}$ & & & & & & \\
\hline$E_{4}$ & 25,14 & 26,1 & 27,99 & 29,48 & 22,73 & 20,07 \\
$E_{5}$ & 24,18 & 26,59 & 23,69 & 31,41 & 29,96 & 24,78 \\
$E_{6}$ & 31,89 & 31,65 & 26,1 & 25,61 & 20,31 & - \\
$E_{8}$ & 35,75 & 37,55 & 31,65 & 29,00 & - & - \\
$E_{9}$ & 30,44 & 35,51 & 36,96 & 29,48 & 31,89 & 31,89 \\
$E_{10}$ & 26,59 & 28,75 & 30,93 & 26,1 & 28,51 & - \\
$E_{11}$ & 34,55 & 28,51 & 35,26 & - & - & - \\
\hline
\end{tabular}

Apêndice 2. Determinaçōes individuais da IgG sêrica (mg/ml) de êguas Mangalarga dias antes do parto.

\begin{tabular}{lcccccc}
\hline $\begin{array}{c}\text { Epoca de } \\
\text { amostragem }\end{array}$ & Parto & $3-6$ & $9-13$ & $16-20$ & $23-26$ & + de 26 \\
\hline $\begin{array}{l}N^{\circ} \text { do } \\
\text { animal }\end{array}$ & & & & & & \\
\hline$E_{1}$ & 24,18 & 9,7 & 16,94 & 28,03 & 24,65 & 29,73 \\
$E_{3}$ & 24,18 & 22,24 & 23,45 & 23,2 & 22,96 & - \\
$E_{7}$ & 28,75 & 21,28 & 24,65 & 29,48 & 22,73 & 24,45 \\
$E_{12}$ & 21,04 & 29,24 & 28,51 & 30,69 & - & - \\
$E_{13}$ & 25,14 & - & - & - & - & - \\
$E_{14}$ & 33,34 & - & - & - & - & - \\
\hline
\end{tabular}


Apêndice 3. Determinações individuais das Ig sérica (unidades ZST e mg/ ml) de potros Anglo-Arabes de 0 a 70 dias de idade.

\begin{tabular}{|c|c|c|c|c|c|c|c|c|}
\hline $\begin{array}{l}\mathrm{N}^{\circ} \text { do } \\
\text { animal }\end{array}$ & & $\mathrm{P}_{4}$ & $\mathrm{P}_{5}$ & $P_{6}$ & $P_{8}$ & $P_{9}$ & $\mathrm{P}_{10}$ & $\mathrm{P}_{11}$ \\
\hline Zero hora & $\begin{array}{l}\mathrm{ZST} \\
\mathrm{mg} / \mathrm{ml}\end{array}$ & $\begin{array}{l}5,00 \\
3,33\end{array}$ & $\begin{array}{r}1,00 \\
-0,03\end{array}$ & $\begin{array}{l}2,00 \\
0,81\end{array}$ & $\begin{array}{l}18,00 \\
14,26\end{array}$ & $\begin{array}{l}13,50 \\
10,48\end{array}$ & $\begin{array}{l}4,25 \\
2,4 /\end{array}$ & $\begin{array}{l}2,50 \\
0,77\end{array}$ \\
\hline $1 \mathrm{dia}$ & $\begin{array}{l}\mathrm{ZST} \\
\mathrm{mg} / \mathrm{ml}\end{array}$ & $\begin{array}{l}38,25 \\
31,28\end{array}$ & $\begin{array}{l}29,50 \\
25,33\end{array}$ & - & $\begin{array}{r}10,00 \\
7,34\end{array}$ & $\begin{array}{l}40,00 \\
32,75\end{array}$ & $\begin{array}{l}38,50 \\
33,25\end{array}$ & $\begin{array}{l}29,50 \\
29,04\end{array}$ \\
\hline 2 dias & $\begin{array}{l}\mathrm{ZST} \\
\mathrm{mg} / \mathrm{ml}\end{array}$ & $\begin{array}{l}36,00 \\
29,38\end{array}$ & $\begin{array}{l}27,00 \\
21,82\end{array}$ & - & $\begin{array}{l}36,00 \\
29,15\end{array}$ & - & - & - \\
\hline 5 dias & $\begin{array}{l}\mathrm{ZST} \\
\mathrm{mg} / \mathrm{ml}\end{array}$ & $\begin{array}{l}31,50 \\
25,60\end{array}$ & $\begin{array}{l}29,00 \\
23,50\end{array}$ & $\begin{array}{l}27,00 \\
21,82\end{array}$ & & $\begin{array}{l}32,75 \\
26,65\end{array}$ & $\begin{array}{l}35,50 \\
28,96\end{array}$ & - \\
\hline 10 dias & $\begin{array}{l}\mathrm{ZST} \\
\mathrm{mg} / \mathrm{ml}\end{array}$ & $\begin{array}{l}29,00 \\
23,50\end{array}$ & $\begin{array}{l}25,00 \\
20,14\end{array}$ & $\begin{array}{l}21,50 \\
17,20\end{array}$ & $\begin{array}{l}28,25 \\
22,87\end{array}$ & $\begin{array}{l}32,00 \\
26,02\end{array}$ & $\begin{array}{l}29,50 \\
23,92\end{array}$ & - \\
\hline 15 dias & $\begin{array}{l}\mathrm{ZST} \\
\mathrm{mg} / \mathrm{ml}\end{array}$ & - & $\begin{array}{l}21,75 \\
17,41\end{array}$ & $\begin{array}{l}16,50 \\
13,00\end{array}$ & & & $\begin{array}{l}32,50 \\
26,21\end{array}$ & $\begin{array}{l}22,00 \\
17,62\end{array}$ \\
\hline 20 dias & $\begin{array}{l}\mathrm{ZST} \\
\mathrm{mg} / \mathrm{ml}\end{array}$ & $\begin{array}{l}25,50 \\
20,56\end{array}$ & $\begin{array}{l}23,50 \\
18,88\end{array}$ & - & $\begin{array}{l}30,50 \\
24,76\end{array}$ & $\begin{array}{l}26,00 \\
20,98\end{array}$ & $\begin{array}{l}23,50 \\
18,88\end{array}$ & $\begin{array}{r}12,50 \\
9,63\end{array}$ \\
\hline 25 dias & $\begin{array}{l}\mathrm{ZST} \\
\mathrm{mg} / \mathrm{ml}\end{array}$ & $\begin{array}{l}24,50 \\
19,72\end{array}$ & $\begin{array}{l}23,50 \\
18,88\end{array}$ & $\begin{array}{l}13,50 \\
10,48\end{array}$ & $\begin{array}{l}29,25 \\
23,71\end{array}$ & & $\begin{array}{l}22,25 \\
17,83\end{array}$ & $\begin{array}{l}23,00 \\
18,46\end{array}$ \\
\hline 30 dias & $\begin{array}{l}\mathrm{ZST} \\
\mathrm{mg} / \mathrm{mI}\end{array}$ & $\begin{array}{l}23,50 \\
18,88\end{array}$ & $\begin{array}{l}23,00 \\
18,46\end{array}$ & $\begin{array}{l}23,25 \\
18,67\end{array}$ & & & $\begin{array}{l}20,00 \\
15,94\end{array}$ & - \\
\hline 40. dias & $\begin{array}{l}\mathrm{ZST} \\
\mathrm{mg} / \mathrm{ml}\end{array}$ & $\begin{array}{l}19,00 \\
15,10\end{array}$ & $\begin{array}{l}27,00 \\
21,82\end{array}$ & $\begin{array}{l}21,50 \\
17,20\end{array}$ & $\begin{array}{l}19,50 \\
15,52\end{array}$ & $\begin{array}{l}23,25 \\
18,67\end{array}$ & $\begin{array}{l}19,75 \\
15,73\end{array}$ & $\begin{array}{l}17,00 \\
13,42\end{array}$ \\
\hline 50 dias & $\begin{array}{l}\mathrm{ZST} \\
\mathrm{mg} / \mathrm{ml}\end{array}$ & $\begin{array}{l}28,50 \\
23,08\end{array}$ & $\begin{array}{l}27,50 \\
22,24\end{array}$ & $\begin{array}{l}20,50 \\
16,36\end{array}$ & $\begin{array}{l}23,00 \\
18,46\end{array}$ & $\begin{array}{l}24,50 \\
19,72\end{array}$ & $\begin{array}{l}22,50 \\
18,04\end{array}$ & $\begin{array}{l}21,00 \\
16,78\end{array}$ \\
\hline 60 dias & $\begin{array}{l}\mathrm{ZST} \\
\mathrm{mg} / \mathrm{mI}\end{array}$ & $\begin{array}{l}26,00 \\
20,98\end{array}$ & $\begin{array}{l}22,00 \\
17,16\end{array}$ & $\begin{array}{l}18,00 \\
13,92\end{array}$ & $\begin{array}{l}21,50 \\
17,20\end{array}$ & $\begin{array}{l}29,00 \\
23,50\end{array}$ & $\begin{array}{l}24,50 \\
19,72\end{array}$ & $\begin{array}{l}15,00 \\
11,74\end{array}$ \\
\hline 70 dias & $\begin{array}{l}\mathrm{ZST} \\
\mathrm{mg} / \mathrm{ml}\end{array}$ & $\begin{array}{l}23,25 \\
18,67\end{array}$ & $\begin{array}{l}23,50 \\
18,42\end{array}$ & $\begin{array}{l}24,00 \\
19,30\end{array}$ & $\begin{array}{l}24,00 \\
19,30\end{array}$ & $\begin{array}{l}26,00 \\
20,98\end{array}$ & $\begin{array}{l}22,00 \\
17,62\end{array}$ & $\begin{array}{l}20,50 \\
16,36\end{array}$ \\
\hline
\end{tabular}


Apêndice 4. Determinações individuais de Ig sërica (unidades $2 S T$ e $\mathrm{mg} / \mathrm{ml}$ ) de potros Mangalarga de 0 a 70 dias de idade.

\begin{tabular}{|c|c|c|c|c|c|c|c|}
\hline $\begin{array}{l}\text { Ep do } \\
\text { Epoca de } \\
\text { amostragem }\end{array}$ & & $\mathrm{P}_{1}$ & $\mathrm{P}_{3}$ & $\mathrm{P}_{7}$ & $\mathrm{P}_{12}$ & $\mathrm{P}_{13}$ & $\mathrm{P}_{14}$ \\
\hline Zero hora & $\begin{array}{l}\mathrm{ZST} \\
\mathrm{mg} / \mathrm{ml}\end{array}$ & $\begin{array}{l}3,00 \\
1,65\end{array}$ & $\begin{array}{l}13,50 \\
10,25\end{array}$ & $\begin{array}{r}11,00 \\
7,91\end{array}$ & $\begin{array}{r}1,00 \\
-0,03\end{array}$ & $\begin{array}{l}17,75 \\
14,05\end{array}$ & $\begin{array}{l}3,50 \\
1,56\end{array}$ \\
\hline 1 dia & $\begin{array}{l}\mathrm{ZST} \\
\mathrm{mg} / \mathrm{ml}\end{array}$ & $\begin{array}{l}23,50 \\
18,35\end{array}$ & $\begin{array}{l}19,15 \\
15,52\end{array}$ & $\begin{array}{l}23,50 \\
17,08\end{array}$ & $\begin{array}{l}13,50 \\
21,99\end{array}$ & $\begin{array}{l}21,50 \\
15,93\end{array}$ & - \\
\hline 2 dias & $\begin{array}{l}\mathrm{ZST} \\
\mathrm{mg} / \mathrm{ml}\end{array}$ & $\begin{array}{l}32,25 \\
26,23\end{array}$ & $\begin{array}{l}18,50 \\
14,68\end{array}$ & $\begin{array}{l}18,50 \\
14,68\end{array}$ & $\begin{array}{l}28,50 \\
23,08\end{array}$ & $\begin{array}{l}22,00 \\
17,62\end{array}$ & $\begin{array}{l}30,50 \\
24,76\end{array}$ \\
\hline 5 dias & $\begin{array}{l}\mathrm{ZST} \\
\mathrm{mg} / \mathrm{ml}\end{array}$ & $\begin{array}{l}29,00 \\
23,50\end{array}$ & $\begin{array}{l}17,50 \\
13,84\end{array}$ & - & $\begin{array}{l}20,50 \\
16,36\end{array}$ & $\begin{array}{l}18,50 \\
14,68\end{array}$ & $\begin{array}{l}24,50 \\
19,72\end{array}$ \\
\hline 10 dias & $\begin{array}{l}\mathrm{ZST} \\
\mathrm{mg} / \mathrm{ml}\end{array}$ & $\begin{array}{l}23,50 \\
18,88\end{array}$ & $\begin{array}{l}17,00 \\
13,42\end{array}$ & $\begin{array}{l}17,25 \\
13,63\end{array}$ & - & $\begin{array}{l}14,00 \\
10,90\end{array}$ & $\begin{array}{l}19,00 \\
15,10\end{array}$ \\
\hline 15 dias & $\begin{array}{l}\mathrm{ZST} \\
\mathrm{mg} / \mathrm{ml}\end{array}$ & $\begin{array}{l}20,50 \\
16,36\end{array}$ & $\begin{array}{l}17,00 \\
13,42\end{array}$ & $\begin{array}{l}21,50 \\
17,20\end{array}$ & - & $\begin{array}{l}17,00 \\
13,42\end{array}$ & $\begin{array}{l}16,50 \\
13,00\end{array}$ \\
\hline 20 dias & $\begin{array}{l}\mathrm{ZST} \\
\mathrm{mg} / \mathrm{ml}\end{array}$ & $\begin{array}{l}20,50 \\
16,36\end{array}$ & $\begin{array}{l}14,00 \\
10,90\end{array}$ & - & $\begin{array}{l}18,75 \\
14,89\end{array}$ & $\begin{array}{l}15,75 \\
12,37\end{array}$ & $\begin{array}{l}32,50 \\
26,44\end{array}$ \\
\hline 25 dias & $\begin{array}{l}\mathrm{ZST} \\
\mathrm{mg} / \mathrm{ml}\end{array}$ & $\begin{array}{l}19,25 \\
15,31\end{array}$ & $\begin{array}{l}15,00 \\
11,74\end{array}$ & $\begin{array}{l}19,00 \\
15,10\end{array}$ & $\begin{array}{r}11,00 \\
8,37\end{array}$ & - & $\begin{array}{l}29,00 \\
23,50\end{array}$ \\
\hline 30 dias & $\begin{array}{l}\mathrm{ZST} \\
\mathrm{mg} / \mathrm{mI}\end{array}$ & $\begin{array}{l}22,00 \\
17,62\end{array}$ & $\begin{array}{l}21,50 \\
17,20\end{array}$ & $\begin{array}{r}12,50 \\
9,63\end{array}$ & $\begin{array}{l}17,00 \\
13,42\end{array}$ & $\begin{array}{l}9,75 \\
7,32\end{array}$ & $\begin{array}{l}16,75 \\
13,21\end{array}$ \\
\hline 40 dias & $\begin{array}{l}\mathrm{ZST} \\
\mathrm{mg} / \mathrm{ml}\end{array}$ & $\begin{array}{l}21,00 \\
16,78\end{array}$ & $\begin{array}{l}23,50 \\
18,88\end{array}$ & - & $\begin{array}{l}15,25 \\
11,95\end{array}$ & $\begin{array}{l}17,00 \\
13,42\end{array}$ & $\begin{array}{l}19,00 \\
15,10\end{array}$ \\
\hline 50 dias & $\begin{array}{l}\mathrm{ZST} \\
\mathrm{mg} / \mathrm{ml}\end{array}$ & $\begin{array}{l}19,50 \\
15,52\end{array}$ & $\begin{array}{l}21,25 \\
16,99\end{array}$ & $\begin{array}{l}16,50 \\
13,00\end{array}$ & $\begin{array}{l}16,50 \\
13,00\end{array}$ & $\begin{array}{l}22,00 \\
17,62\end{array}$ & $\begin{array}{l}24,50 \\
19,72\end{array}$ \\
\hline 60 dias & $\begin{array}{l}\mathrm{ZST} \\
\mathrm{mg} / \mathrm{ml}\end{array}$ & - & $\begin{array}{l}23,00 \\
18,46\end{array}$ & $\begin{array}{l}26,50 \\
21,40\end{array}$ & $\begin{array}{l}23,00 \\
18,46\end{array}$ & $\begin{array}{l}21,00 \\
16,78\end{array}$ & $\begin{array}{l}28,00 \\
22,55\end{array}$ \\
\hline 70 dias & $\begin{array}{l}\mathrm{ZST} \\
\mathrm{mg} / \mathrm{mI}\end{array}$ & $\begin{array}{l}27,25 \\
22,03\end{array}$ & $\begin{array}{l}28,50 \\
23,08\end{array}$ & $\begin{array}{l}32,00 \\
26,02\end{array}$ & $\begin{array}{l}23,00 \\
18,46\end{array}$ & $\begin{array}{l}23,50 \\
18,88\end{array}$ & $\begin{array}{l}28,50 \\
22,62\end{array}$ \\
\hline
\end{tabular}


Apêndice 5. Determinações individuais da PT $\left(\begin{array}{l}\% \\ 0\end{array}\right)$ do colostro de êguas PSI.

\begin{tabular}{lllc}
\hline No animal & Data parto & PT $(\%)$ & $\begin{array}{c}\text { IgG estimada } \\
40 \% \text { PT }(\mathrm{mg} / \mathrm{mI})\end{array}$ \\
\hline $\mathrm{E}_{4}$ & $10 / 10 / 87$ & 21,22 & 84,88 \\
$\mathrm{E}_{5}$ & $19 / 10 / 87$ & 18,78 & 75,12 \\
$\mathrm{E}_{6}$ & $31 / 10 / 87$ & 23,16 & 92,64 \\
$\mathrm{E}_{8}$ & $08 / 11 / 87$ & 23,81 & 95,24 \\
$\mathrm{E}_{10}$ & $17 / 11 / 87$ & 22,79 & 91,16 \\
\hline
\end{tabular}

Apêndice 6. Determinaçōes individuais da PT $(\%)$ do colostro de éguas Man galarga.

\begin{tabular}{llcc}
\hline$N^{\circ}$ animal & Data parto & PT (⿺⿻) $\begin{array}{c}\text { IgG estimada } \\
40 \% \text { PT (mg/m1) }\end{array}$ \\
\hline$E_{1}$ & $20 / 09 / 87$ & 7,86 & 31,44 \\
$E_{3}$ & $28 / 09 / 87$ & 6,96 & 27,84 \\
$E_{7}$ & $16 / 11 / 87$ & 8,98 & 35,92 \\
$E_{13}$ & $30 / 12 / 87$ & 11,30 & 45,20 \\
$E_{14}$ & $23 / 01 / 88$ & 23,11 & 92,44 \\
\hline
\end{tabular}

